\title{
IMPACT OF FATTY ACYL COMPOSITION AND QUANTITY OF TRIGLYCERIDES ON BIOACCESSIBILITY OF DIETARY CAROTENOIDS
}

\author{
THESIS \\ Presented in Partial Fulfillment of the Requirements for \\ the Degree Master of Science in the Graduate \\ School of The Ohio State University \\ By \\ Tianyao Huo, M.S. \\ $* * * * *$ \\ The Ohio State University \\ 2007
}

Thesis Committee:

Professor Mark L. Failla, Advisor Approved by

Professor Martha A. Belury

Professor Steven J. Schwartz

Advisor

College of Education and Human Ecology 


\section{ABSTRACT}

A carotenoid-rich salad meal with varying amounts and types of triglycerides (TG) was digested using simulated gastric and small intestinal conditions. Xanthophylls (lutein and zeaxanthin) and carotenes ( $\alpha$-carotene, $\beta$-carotene and lycopene) in chyme and micelle fraction were quantified to determine digestive stability and the efficiency of micellarization ("bioaccessibility"). Micellarization of lutein (+zeaxanthin) significantly exceeded $\alpha$ - and $\beta$-carotenes which significantly exceeded that of lycopene for all test conditions. Micellarization of carotenes, but not lutein (+zeaxanthin), was enhanced ( $P<$ $0.05)$ by addition of TG $(2.5 \% \mathrm{v} / \mathrm{w})$ to meal and dependent on fatty acyl length of chains in structured TG $(\mathrm{c} 18: 1>\mathrm{c} 8: 0>\mathrm{c} 4: 0)$. The degree of unsaturation of $\mathrm{c} 18$ fatty acyl chains in TG added to the salad purée did not significantly alter the efficiency of micellarization of carotenoids. Relatively low amounts of triolein and canola oil (0.5$1 \%)$ were required for maximum micellarization of carotenes, but more oil $(\sim 2.5 \%)$ was required when TG with medium chain length saturated fatty acyl groups (e.g., trioctanoin and coconut oil) was added to salad. Uptake of lutein and $\beta$-carotene by Caco-2 cells also was examined by exposing cells to micelles generated during simulated digestion of salad purée with either triolein or trioctanoin. Cell accumulation 
of $\beta$-carotene was independent of fatty acyl composition of micelles, whereas lutein uptake was slightly, but significantly, increased from samples with digested triolein compared to trioctanoin. The results show that in vitro transfer of $\alpha$-carotene, $\beta$-carotene and lycopene from chyme to mixed micelles during digestion requires minimal $(0.5-1 \%)$ lipid content in the meal and is affected by length of fatty acyl chains, but not degree of unsaturation, in TG. In contrast, fatty acyl chain length has limited, if any, impact on carotenoid uptake by small intestinal epithelial cells. These data suggest that the amount of TG in a typical meal does not limit the bioavailability of carotenoids.

Reproduced with permission from J.Agric Food. Chem. 2007, 55 (22) , 8950-8957. Copyright 2007 American Chemical Society 
Dedicated to my parents 


\section{ACKNOWLEDGMENTS}

I extend my sincere gratitude to my mentor Dr. Mark Failla for his guidance in all aspects of this endeavor. I will never forget his scientific and patient advice, his broad knowledge, his enthusiasm in research, and his passion in working with students.

I would also like to thank my co-advisor, Dr. Steven Schwartz and my committee member, Dr. Martha Belury, for their professional and personal support, scientific insights, and guidance.

I am grateful to Dr. Mario Ferruzzi for providing the salad meal, insightful comments on my experimental results and critical review of my manuscript. I appreciate Dr. Earl Harrison's helpful guidance, as well as his critical review of my manuscript.

Thank you to Sagar Thakkar for helpful discussions about our research, assistance in improving my English, and friendship.

Thank you to Karina Polar-Cabrera, Dr. Chureeporn Chitchumroonchokchai, Jung Kim, Kelly Walsh and Becky Melick, for all your assistance and your friendship. I thank my parents and all of other family members for their support and care. Thank you to Chris Lee, my best friend, for your encouragement for these two years. 
This research was supported in part by the Graduate Research Enhancement Grant Program of Ohio Agriculture Research and Development Center (OARDC). I am also grateful for the financial support from the interdisciplinary Ph.D. Program in Nutrition. 


\section{VITA}

August, 1980.........................Born - Zhenjiang, Jiangsu, China

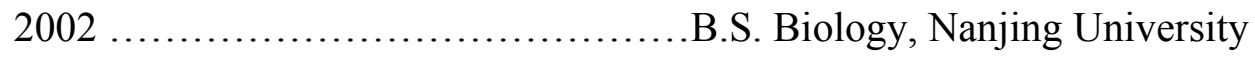

2004 M.S. Zoology, Nanjing University

2004-present .Graduate Research Associate, The Ohio State University

\section{Publications}

RESEARCH PUBLICATION

1. Failla ML, Huo T, Thakkar SK (2008). In vitro screening of relative bioavailability of carotenoids from foods. (review) Asian Pacific J Clin. Nutr. In press.

2. Huo T, Ferruzzi MG, Schwartz SJ, Failla ML (2007) Impact of fatty acyl composition and quantity of triglycerides on bioaccessibility of dietary carotenoids. J. Agric. Food Chem., 55(22): 8950-8957

3. Ding J, Jing X, Huo T, Cao D, Huang C. (2004) Effect of perilla oil on reducing triglyceride and cholesterol level in serum of hyperlipidemia model rats. China Fats and Oils. 29(10): 61-64.

4. Jin A, Chen Y, Ding J, Huo T, Huang C. (2004) Impact of perilla oil on the antioxidative system of the brain in SSA mice. Chinese J. Gerontology. 24(7): 648650.

5. Ding J, Jin A, Shi L, Huo T, Huang C. (2004) Effect of Spirulina on antioxidation ability of liver during CCl4 induced chronic liver injury in mice. J. Lake Sci. 16 (4): 343-348.

6. Huo T, Jin A, Chen Y, Ding J, Huang C. (2004) Effect of perilla oil on GSH content vii 
of the brain in SSA-mice induced by D-galactose. China Fats and Oils. 29 (2): 68-70.

7. Chen Y, Jin A, Huo T, Lv J, Huang C. (2003) Observations on the effects of Artemia powder on anti-stress actions of Mus musculus, J. Nanjing Normal Univ. (Natural Science), 26 (1): 88-91.

8. Huo T, Huang C, Chen Y. (2002) Effects of algae Spirulina maxima on hyperlipemic rats. J. Nanjing Normal Univ. (Natural Science), 4 (2): 40-44.

9. Liu G, Chen Y, Yang X, Huo T, Huang C. Expression of recombinant hTPO genes in HepG2 and its influences on the expression of TPO receptor, J. Nanjing Normal University (Natural Science), 2003, 26 (1): 92-95.

Abstracts

1. Failla ML, Huo T, Thakkar SK (2007) In vitro screening of relative bioavailability of carotenoids and other dietary lipids from foods. $10^{\text {th }}$ Asian Congress of Nutrition.

2. Huo T, Ferruzzi MG, Belury MA, Schwartz SJ, and Failla ML. (2007) Impact of triglyceride (TG) structure on bioaccessibility of dietary carotenoids using simulated digestion and Caco-2 cell model. Institute of Food Technology. (Abstract 010-14)

3. Huo T., Ferruzzi MG., Belury MA., Schwartz SJ, and Failla ML. (2007) impact of amount and triglyceride (TG) structure on micellarization of dietary carotenoids during simulated digestion. FASEB J. 21: A730 (Abstract 701.15).

\section{FIELD OF STUDY}

Major Field: Human Ecology

Area of Emphasis: Human Nutrition 


\section{TABLE OF CONTENTS}

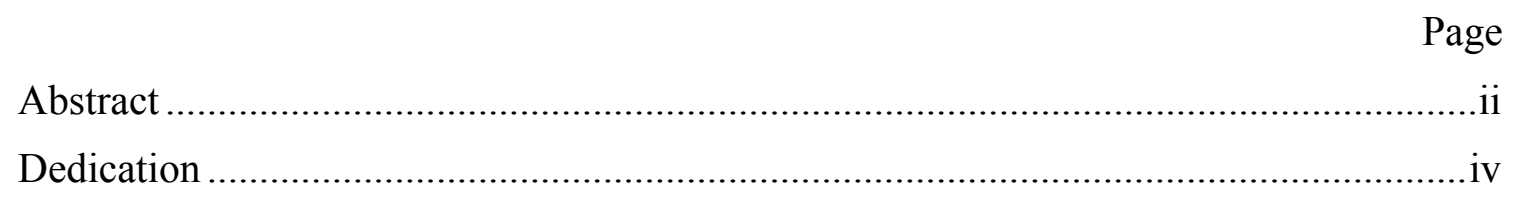

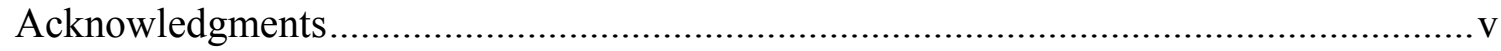

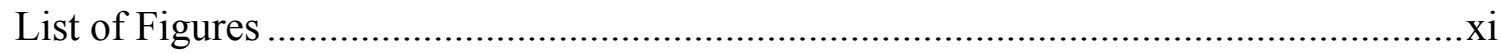

List of Tables .....................................................................................................

Chapters

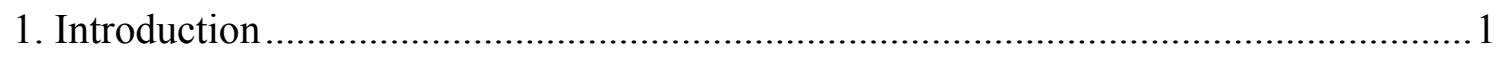

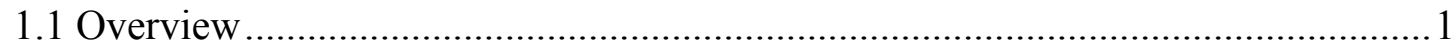

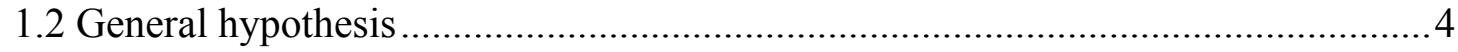

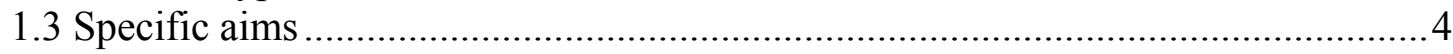

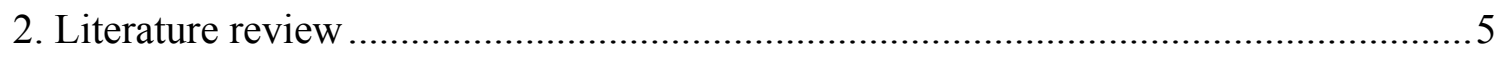

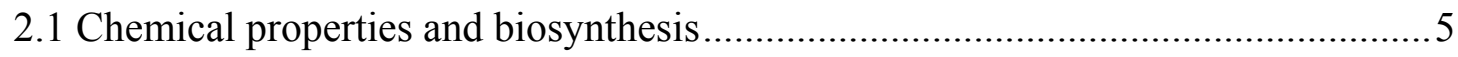

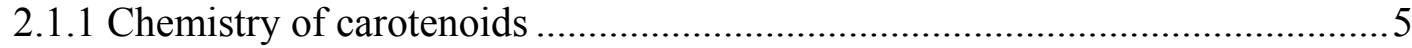

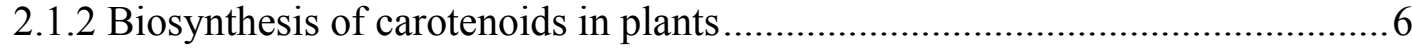

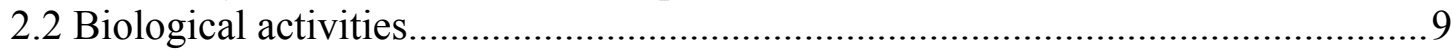

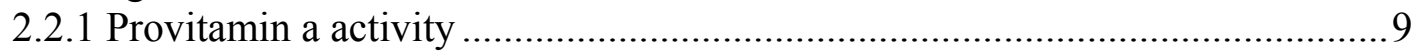

2.2.2 Antioxidant and photoprotective activity............................................. 11

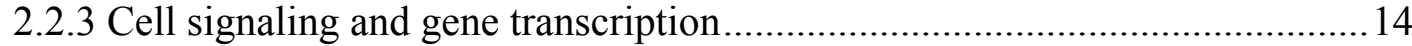

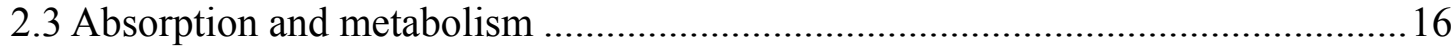

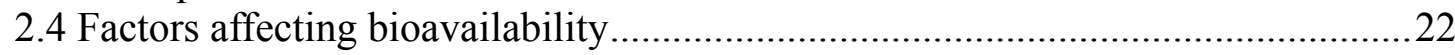

2.4.1 Physicochemical properties of carotenoids ............................................... 22

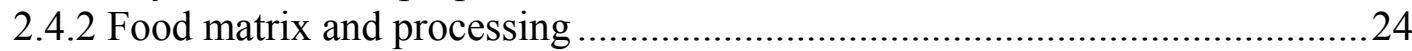

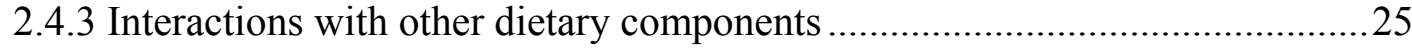

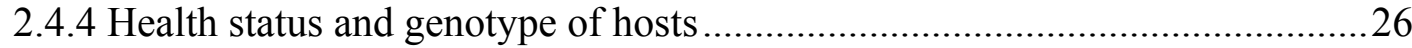

2.5 Influence of dietary lipids the absorption of carotenoids...................................27

2.6 Models for investigating pre-absorptive metabolisms of dietary carotenoids ........30

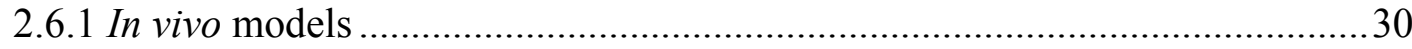

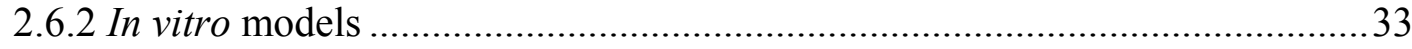

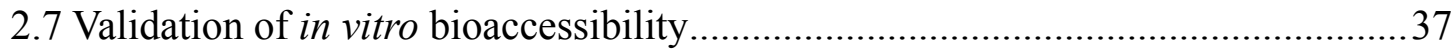

3. Impact of fatty acyl composition and quantity of triglycerides on bioaccessibility of dietary carotenoids 


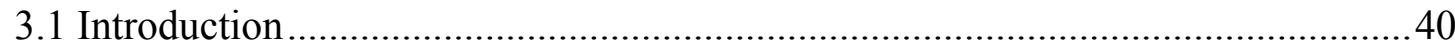

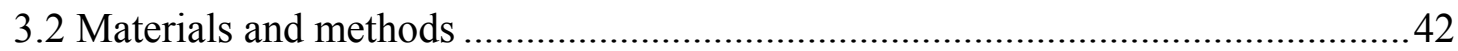

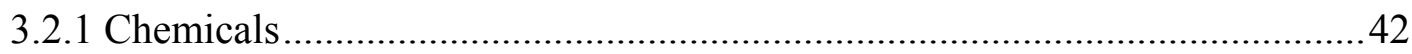

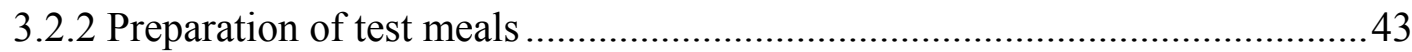

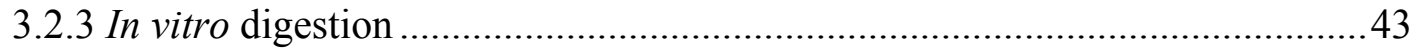

3.2.4 Uptake of carotenoids by caco-2 human intestinal cells ...................................4

3.2.5 Extraction of carotenoids from salad purée, chyme and micellar fraction ......45

3.2.6 Carotenoid analysis by HPLC .......................................................................46

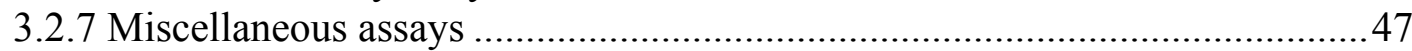

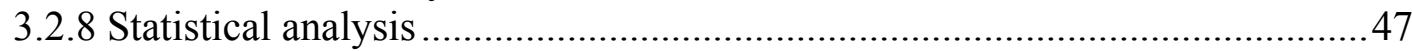

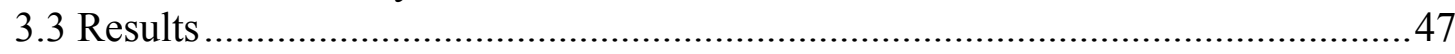

3.3.1 Carotenoid profile in salad before and after simulated digestion ....................47

3.3.2 Effect of TG with different fatty acyl groups on micellarization of carotenoids during simulated digestion of salad purée................................................................4 3.3.3 Effect of acyl chain length on uptake of micellar carotenoids by caco-2 cells

4 Discussion.

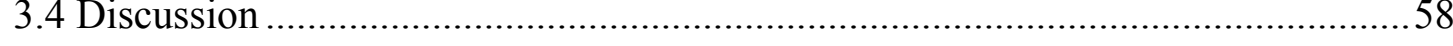

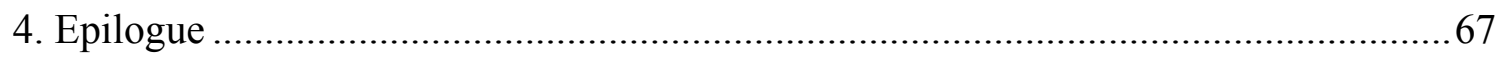

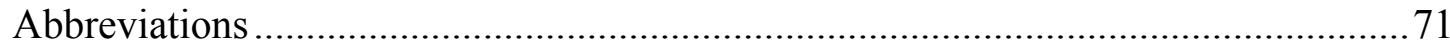

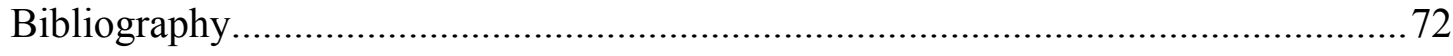




\section{LIST OF FIGURES}

Figure 2.1 Chemical structures and biosynthesis pathway of carotenoids in plants.... 7

Figure 2.2 Digestion and absorption of carotenoids ......................................... 19

Figure 2.3 Graphical representation of coupled in vitro digestion/Caco-2 cell uptake model to assess carotenoid bioaccessibility.................................... 36

Figure 3.1 HPLC profile of representative chromatograms of carotenoids from the test salad purée.

Figure 3.2 Addition of triolein to salad purée increases micellarization of $\beta$-carotene during simulated digestion more efficiently than trioctanoin.

Figure 3.3 Fatty acyl chain length and amount of TG affect micellarization of $\alpha$ carotene, and lycopene, but not lutein + zeaxanthin.

Figure 3.4 Maximum micellarization of carotenoids during simulated digestion of salad is dependent on type and amount of dietary oils 56

Figure 3.5 Fatty acyl chain length in dietary TG has minimum impact on efficiency of uptake of micellarized lutein and $\beta$-carotene by Caco- 2 cells. 59 


\section{LIST OF TABLES}

Table 2.1 Biological activities of carotenoids........................................................... 10

Table 2.2 Carotenoid content of common foods ( $\mu \mathrm{g} / 100 \mathrm{~g}$ editble portion). (data are from USDA carotenoid database for U.S. food- 1998)............................ 17

Table 2.3 Factors affecting bioavailability of carotenoids........................................ 23

Table 2.4 Influences of dietary fat on carotenoid absorption .....................................2 28

Table 3.1 Chain length, but not degree of unsaturation of acyl groups in TG affects micellarization of carotenoids during in vitro digestion of salad............... 52 


\section{CHAPTER 1}

\section{INTRODUCTION}

\subsection{Overview}

Carotenoids are red, orange or yellow lipophilic pigments synthesized by photosynthetic organisms including procaryotes, algae, and avascular and vascular plants. Among the more than 600 species of carotenoids present in nature, approximately 60 carotenoids have been identified in human diets with approximately 20 of these detected in human plasma or tissues. $\beta$-carotene (BC) has traditionally been the carotenoid of greatest interest to biomedical researchers because of its established role as a precursor for vitamin A. Vitamin A is essential for vision and cellular differentiation. Studies during the past decade have suggested that both pro-vitamin A and other carotenoids lacking pro-vitamin A activity may decrease the risks of cardiovascular diseases, age-related macular degeneration, infectious diseases, and cancers of the skin and prostate (1-4). Such health benefits of carotenoids may be due to one or more of the reported biological activities of carotenoids and their metabolites. Due to their conjugated double bond system, these compounds are excellent quenchers of singlet oxygen and scavengers of peroxyl radicals (5). Carotenoids also have been 
reported to stimulate gap junction communication in a vitamin $\mathrm{A}$ independent manner (6).

Provitamin A carotenoids represent the primary source of vitamin A for individuals in developing countries who lack access to vitamin A fortified foods and supplements. Generally, provitamin A carotenoids are considered safe since hydrolysis by $\beta$-carotene mono-oxygenase I (BCO1) activity is regulated inversely with vitamin $\mathrm{A}$ status $(7,8)$. However, two intervention trials showed increased risk for lung cancer when smokers consuming alcoholic beverages were supplemented chronically with high doses of $\mathrm{BC}(9,10)$. This suggested prooxidant effects of $\mathrm{BC}$ when the doses far exceeded the normal dietary intake. This finding provided impetus for systematic investigation of the health promoting activities of other carotenoids that are relatively abundant in the diet, including lutein (LUT), zeaxanthin (ZEA), $\beta$-cryptoxanthin (CTX), $\alpha$-carotene (AC), lycopene (LYC), and fucoxanthin.

The beneficial effects of carotenoids require delivery of the ingested compound or its metabolites to target tissues. Carotenoids in foods are released from food matrix to oil droplets during early stages of digestion. The oil droplets are degraded in the small intestine by lipases secreted by exocrine pancreas and bile salts. This is associated with transfer of carotenoids to much smaller particles called micelles which are composed of bile salts, fatty acids, monoacylglycerols, phospholipids, cholesterol and other minor lipophilic compounds. Incorporation into mixed micelles mediates delivery of carotenoid to the brush border surface of enterocytes. The efficiency of the partitioning of ingested carotenoids and other lipophilic compounds into micelles is increasingly 
referred to as bioaccessibility. Within enterocytes, a portion of pro-vitamin A carotenoids are converted to retinyl esters (RE). RE and intact carotenoids are incorporated into chylomicrons and secreted to lymph for delivery to peripheral tissues. Bioavailability is the term commonly used for the transfer of ingested carotenoids from food matrix to target tissues $(11,12)$.

The absorption of dietary fatty acyl groups is highly efficient. In contrast, the bioavailability of carotenoids is generally low and affected by numerous factors including chemical speciation, physical state, food matrix, styles of food processing, dietary components, gut health, nutritional status, and genotype (13). Dietary factors that have been shown to affect carotenoid bioavailability include lipids, protein, fiber, phytosterols and other carotenoids. Dietary lipid is potent promoter of carotenoid absorption $(14,15)$. However, excessive dietary fat, and especially saturated fat, increases the risk of cardiovascular diseases, type II diabetes mellitus, and certain types of cancer $(16,17)$.

The 2005 Dietary Guidelines for Americans recommend decreasing fat intake and increasing the ratio of unsaturated to saturated fats. Information is needed about properly balancing fat intake and efficient absorption of fat soluble nutrients and nonessential, but health promoting, lipophilic compounds (18). My research has addressed the influence of amount and type of triglycerides (TG), the predominant lipids in the human diet, on the bioaccessibility of carotenoids from vegetables. There are three key processes required for carotenoid absorption. These include 1) transfer of carotenoids from the food matrix to the micelles during digestion, 2) uptake of carotenoids in 
micelles by absorptive epithelial cells, and 3) incorporation of carotenoids and RE into chylomicrons and their secretion into the lymph. Dietary lipids likely affect the absorption of carotenoids by modifying one or more of these processes and I have examined the first two processes associated with absorption. In vitro digestion and Caco-2 human intestinal cells were used at models to examine these processes. The general hypothesis and specific aims of my thesis research project follow.

\subsection{General hypothesis:}

The micellarization of carotenoids during small intestinal digestion, and the uptake of carotenoids from micelles by enterocytes will be affected by the amount and fatty acyl composition of TG in a meal.

\subsection{Specific aims:}

1) To examine the effects of type and quantity of structured lipids/dietary oils on micellarization of carotenoids from foods by simulated gastric and small intestinal digestion of a western salad.

2) To determine the impact of TG fatty acyl chain length on uptake of carotenoids in micelles generated during simulated digestion of salad by Caco-2 human intestinal cells. 


\section{CHAPTER 2}

\section{LITERATURE REVIEW}

\subsection{Chemical properties and biosynthesis}

\subsubsection{Chemistry of carotenoids}

Carotenoids are a family of yellow, orange and red lipophilic plant pigments present in fruits and vegetables. These compounds are tetra-terpenoids characterized by conjugated double-bonds with cyclic or acyclic structures at the ends of the chain. Among 600 carotenoids which are found in nature, approximately $10 \%$ are present in the human diet, and about 3\% are detected in human plasma. Carotenoids are produced by photosynthetic plants, algae, fungi and bacteria. Animals do not synthesize carotenoids, but rather obtain these compounds from their diets. Carotenoids are often cleaved, isomerized or covalently modified during metabolism as will be discussed in detail below (19).

Carotenoids generally are classified as either carotenes or xanthophylls. Carotenes are also called hydrocarbon carotenoids characterized as conjugated hydrocarbon compounds lacking oxygen atoms. The most abundant carotenes in human diets include LYC, AC and BC. LYC lacks cyclic end groups and is the precursor for synthesis of 
AC and BC. Xanthophylls are also called oxy- carotenoids and are more hydrophilic than carotenes because they have one or more functional groups containing oxygen, including hydroxyl, methoxyl, carboxyl, oxo, epoxy and keto groups. LUT, ZEA and CTX are xanthophylls present in common foods. Xanthophylls in plant foods often exist as mono- and di-esters that are more hydrophobic than their non-esterified analogues.

Most carotenoids are present in plants in the all-trans (or all-E) configuration. During food processing, or in the presence of light, heat and acids, the proportion of cis (or Z) isomers may increase significantly (20). Isomeric structure can affect the bioavailability and biological activity of carotenoids as discussed in the subsequent sections. Both trans- and cis-isomers are present in body fluids and tissues.

\subsubsection{Biosynthesis of carotenoids in plants}

The pathway for carotenoid biosynthesis is shown in Figure 2.1. Biosynthesis of carotenoids occurs on membranes of chloroplasts, chromoplasts and amyloplasts in plant cells. Carotenoids are derived from isopentenyl diphosphate (IPP), as all products of the plastidic isoprenoid synthesis pathway. Two distinct pathways exist for IPP production, i.e., the cytosolic mevalonic acid pathway and the plastidic methylerythritol 4-phosphate (MEP) pathway (21). IPP is subject to a sequential series of condensation reactions to form geranylgeranyl pyrophosphate (GGPP), a key intermediate compound in the synthesis of a variety of bioactive phytochemicals, that include carotenoids, chlorophylls, tocotrienols, tocopherols and phylloquinones. Phytoene synthease (PSY) condenses two molecules of GGPP to generate one molecule of phytoene. Phytoene is 


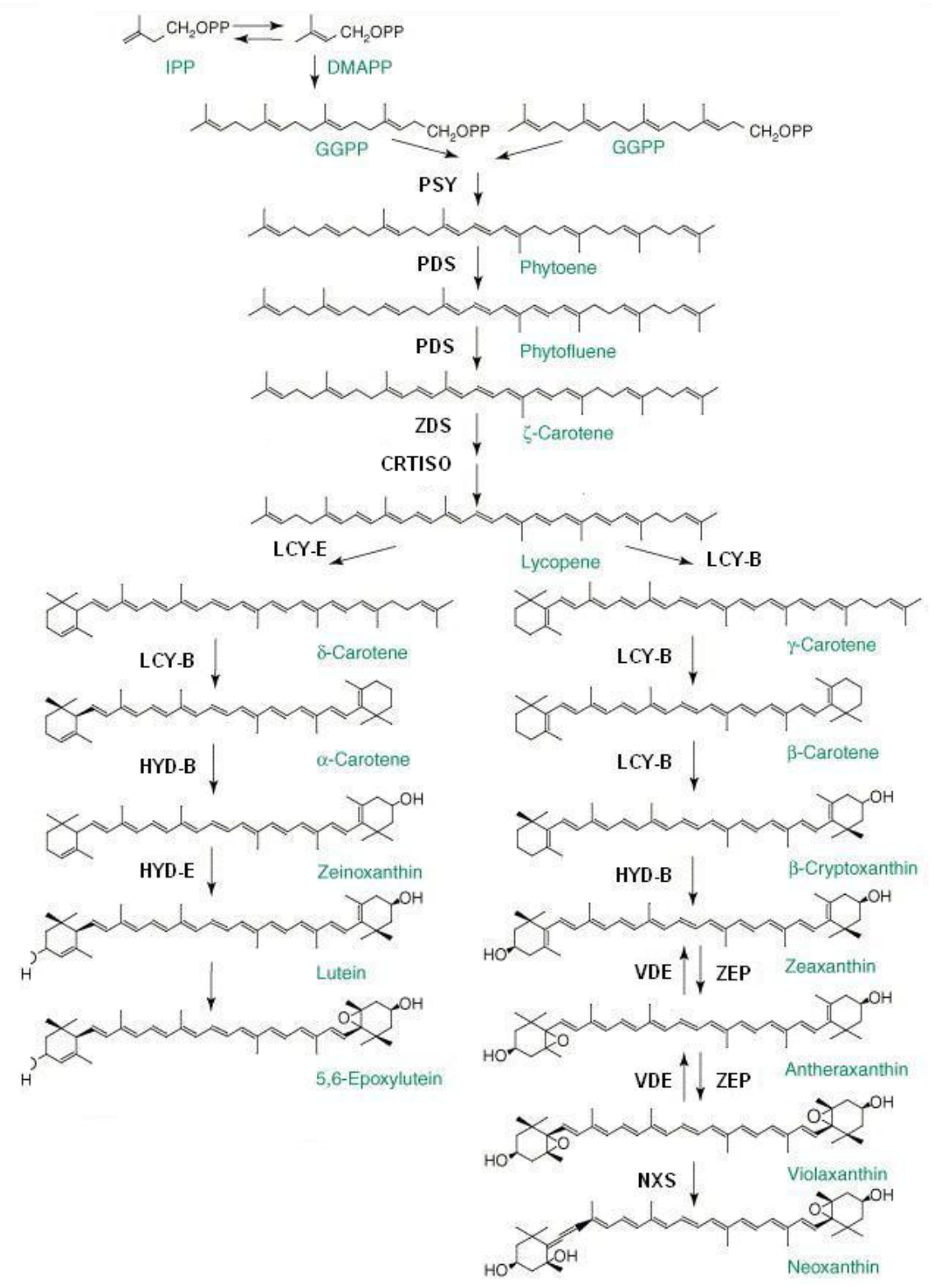

Figure 2.1: Chemical structures and biosynthesis pathway of carotenoids in plants

Abbreviations: GGPP (geranylgeranyl pyrophosphate); Phytoene synthase (PSY); phytoene desaturase (PDS); $\zeta$-carotene desaturase (ZDS); carotene isomerase (ISO); LCY-B (lycopene $\beta$ cyclase); LCY-E (lycopene $\varepsilon$-cyclase); CHY (carotenoid hydrolase); ZEP (zeaxanthin epoxidase); VDE (violaxanthin deepoxidase); NXS (neoxanthin synthase). Modified from the reference (168). 
produced as a 15-cis isomer, and then converted to all-trans derivatives. Two plant desaturases, phytoene desaturase (PDS) and $\zeta$-carotene desaturase (ZDS), catalyze similar dehydrogenation reactions by introducing four double bonds to form cis isomers of lycopene. Since PDS and ZDS introduce cis double bonds, the carotenoid isomerase (CRTISO) converts cis - lycopene to the all-trans form. $\zeta$-carotene desaturase (ZDS), catalyze similar dehydrogenation reactions by introducing four double bonds to form cis isomers of lycopene. The carotenoid isomerase (CRTISO) converts cis - lycopene to the all-trans form.

The carotenoid biosynthetic pathway has two main branches from lycopene. Either $\beta$ - ring or $\varepsilon$ - ring is generated by lycopene $\beta$ - cyclase (LCY-B) or lycopene $\varepsilon$ cyclase (LCY-E), respectively (Figure 2.1). Two $\beta$-rings lead to the $\beta, \beta$ branch (BC and its oxidative derivatives, as ZEA, violaxanthin, antheraxanthin, and neoxanthin), whereas one $\beta$ and one $\varepsilon$ - ring lead to the $\beta, \varepsilon$ branch (AC and its derivatives, such as zeinoxanthin and LUT). Hydroxyl groups are added to AC or BC by carotenoid hydroxylases to form xanthophylls. ZEA is generated from addition of hydroxyl groups to the 3 and 3' positions of the end rings of BC, while LUT is generated from addition of the two hydroxyl groups to AC. ZEA can be further oxidized to antheraxanthin and violaxanthin by zeaxanthin epoxidase (ZEP). Conversion of violaxanthin to neoxanthin is catalyzed by neoxanthin synthase (NXS). Addition of keto groups at the 4 and 4' position of zeaxanthin via a ketolase yields astaxanthin (AST), a prominent carotenoid in marine microalgae and the major pigment in salmon, trout and most crustaceans. 
Epoxidation of these 40 carbon carotenoids also generates a large number of epoxy carotenoids.

\subsection{Biological activities}

Epidemiological studies have revealed that ingestion of carotenoid-rich diets is associated with lower risk of cataracts, age-related ocular degeneration, cardiovascular diseases, and skin, breast, and prostate cancers. In vivo and in vitro studies have demonstrated that these health promoting effects are associated with a number of biological activities of carotenoids, including provitamin A activity, antioxidant activities, influences on intercellular communication through gap junctions, cellular signaling and gene transcription (Table 2.1).

\subsubsection{Provitamin A activity}

Vitamin A is current a general term to describe retinol and other compounds which exhibit biological activity and includes retinal, retinoic acid, RE and their isomers (22). RE from animal sources and provitamin A carotenoids from plant sources are the major dietary forms of vitamin A. Thus, provitamin A carotenoids in fruits and vegetables are predominant source of vitamin A for vegetarians or people in developing countries who seldom consume meat. Of the more than 600 species of carotenoids in nature, approximately 50 carotenoids are pro-vitamin A containing 1-2 $\beta$ - ionone rings (23).

Ten carotenoids possessing pro-vitamin A activities have been detected in vegetables. These include $\mathrm{BC}, \mathrm{AC}, \gamma$-carotene, $\beta$-zeacarotene, $\beta$-carotene-5,6-epoxide, $\beta$-carotene5,8-epoxide, CTX, cryptoxanthin-5,6-epoxide, 3'-hydroxy- $\alpha$-carotene and cryptocapsin. 


\begin{tabular}{|c|c|c|c|}
\hline & Biological function & Compound & Ref. \\
\hline $\begin{array}{l}\text { Provitamin A } \\
\text { activity }\end{array}$ & $\begin{array}{l}\text { Convert to retinol by cleavage of } \\
\mathrm{BCO} 1 \text { and } \mathrm{BCO} 2\end{array}$ & $\mathrm{BC}, \mathrm{AC}, \mathrm{CTX}^{*}$ & $(24-27)$ \\
\hline \multirow[t]{2}{*}{ Antioxidant activity } & Photoprotection of eyes and skin & LUT, ZEA, BC & $(2,28,29)$ \\
\hline & Prevention of LDL oxidation & LUT, ZEA, AST, LYC & $(30-32)$ \\
\hline \multirow{3}{*}{$\begin{array}{l}\text { Cell signaling and } \\
\text { gene transcription }\end{array}$} & Cell cycling regulation & LYC & $(33,34)$ \\
\hline & $\begin{array}{l}\text { Inhibition of cancer cell } \\
\text { proliferation and stimulation of } \\
\text { cell differentiation }\end{array}$ & $\begin{array}{l}\mathrm{BC}, \mathrm{LYC}, \\
\text { cleavage product of } \mathrm{BC}\end{array}$ & $(35-39)$ \\
\hline & $\begin{array}{l}\text { Enhanced gap junction } \\
\text { communication }\end{array}$ & $\begin{array}{l}\text { AST, } \\
\text { non-provitamin A } \\
\text { carotenoids }\end{array}$ & $(40)$ \\
\hline $\begin{array}{l}\text { Provitamin A } \\
\text { independent gene } \\
\text { regulation }\end{array}$ & $\begin{array}{l}\text { Induction of Phase I and Phase II } \\
\text { enzyme }\end{array}$ & $\begin{array}{l}\beta \text {-apo-8'-carotenal, } \\
\text { CTX, or AST }\end{array}$ & $(41)$ \\
\hline
\end{tabular}

Table 2.1: Biological activities of carotenoids 
The most abundant and well-studied pro-vitamin A carotenoid in the human diet is BC. In small intestinal epithelial cells or hepatocytes, BC and other pro-vitamin A can be cleaved by $\mathrm{BCO} 1$ to retinal. Retinal can be reduced to retinol by retinal reductase and be esterified to RE by lecithin: retinol acyltransferase (LRAT) for secretion to lymph via chylomicrons or for storage within tissues. Vitamin A and its metabolites are essential for vision, embryo development, cell differentiation and immune function. 11-cis-retinal participates as the chromophore cofactor for rhodopsin in the photo-transduction process in the retina. Retinoic acids and several other oxidized metabolites of vitamin A regulate cellular proliferation, differentiation and signaling by serving as activating ligands of

retinoic acid receptor $(\mathrm{RAR})$ and retinoid $\mathrm{X}$ receptor $(\mathrm{RXR})$ nuclear receptors. All-trans retinoic acid activates RAR and 9-cis retinoic acid can activate both RAR and RXR. Activated RXR forms heterodimers with RAR and other members of the nuclear hormone receptors super-family, including peroxisome proliferators-activated receptor (PPAR), vitamin D receptor, thyroid hormone receptor, liver $\mathrm{X}$ receptor (LXR) and other "orphan" receptors $(26,42)$. These heterodimers bind to cis recognition sequences in the promoter regions of target genes to modulate the expression of numerous enzymes, extracellular matrix proteins, growth factors and transcription factors, thus regulating numerous cellular responses and metabolic pathways.

\subsubsection{Antioxidant and photoprotective activity}

Aerobic organisms require oxygen for respiration. Reactive oxygen species (ROS) may be generated in cells during the aerobic metabolism. ROS include oxygen ions, free 
radicals and peroxides. Excess ROS can damage lipids, DNA and proteins to induce various biochemical processes that can lead to cardiovascular diseases, cancer, and some neurodegenerative diseases (43). Carotenoids are excellent scavengers of two types of ROS, singlet oxygen $\left({ }^{1} \mathrm{O}_{2}\right)$ and peroxyl radicals. They are also effective deactivators of electronically excited molecules which are involved in generation of radicals and singlet oxygen.

Carotenoids usually quench singlet oxygen physically or chemically. The efficiency of physical quenching greatly exceeds chemical quenching and involves direct energy transfer from the singlet oxygen to the carotenoid molecule to generate ground state oxygen and a triplet or excited carotenoid. The carotenoid then returns to the ground state by dissipating its energy by interaction with the surrounding solvent molecules. The efficacy of carotenoids for physical quenching is related to the number of conjugated double bonds in the molecule. The greater the number of conjugated double bonds, the lower the triplet energy level. LUT, BC, AC, ZEA, and $\beta$-cryptoxanthin (CTX) are all highly active quenchers of singlet oxygen. Lycopene, the open ring carotene, is the most efficient quencher of singlet oxygen (44).

Peroxyl radicals are generated during the chain-reaction of auto-oxidation of lipids. However, the chain-reaction can be interrupted by chain-breaking antioxidants. The antioxidant radical is not sufficiently reactive to propagate the chain of lipid peroxidation, Rather, it decays by reaction with another radical forming stable product or is recycled by another antioxidant to terminate the chain reaction. Carotenoids may 
scavenge radicals in an initial step that involves one or more possible reactions, including electron transfer, allylic hydrogen abstraction, and addition $(5,45)$.

$$
\begin{array}{ll}
\mathrm{CAR}+\mathrm{ROO} \cdot-\mathrm{CAR}^{+}+\mathrm{ROO}^{-} & (\text {Electron transfer }) \\
\mathrm{CAR}+\mathrm{ROO} \cdot-\mathrm{CAR} \cdot+\mathrm{ROOH} & (\text { Hydrogen abstraction) } \\
\mathrm{CAR}+\mathrm{ROO} \cdot->\text { ROOCAR} \cdot & \text { (Addition) }
\end{array}
$$

Several function properties of carotenoids result from their antioxidant activities. In plants, carotenoids are essential components of the photosynthetic system, where they function in the light-harvesting process, photo-protection, singlet oxygen scavenging, and dissipation of excess energy from excited chlorophylls (46). LUT and ZEA accumulate in the human macula and lens where they appear to serve similar photoprotective functions in plants. Patients with age-related macular degeneration have significantly lower LUT and ZEA levels in retina than those from age-matched control (27). Carotenoids also protect human skin against UV light-induced photo-oxidative stress, preventing erythema formation, premature aging and cancer, as well, other diseases associated with oxidative stress in this organ (29).

Oxidation of low-density lipoproteins (LDL) is a major contributing factor for the initiation and progression of atherosclerotic lesions. A widely accepted model is that oxidized LDL particles are recognized and engulfed by monocytes/macrophages. Accumulation of excess oxidized LDL in monocytes/macrophages results in their conversion to foam cells and formation of fatty streaks that represent early markers of arterial damage. The presence of foam cells in the vessel wall also induces inflammation 
leading to additional oxidative stress and proliferation of the surrounding smooth muscle cells which results in progressive narrowing of the artery (47). LUT and AST have been reported to decrease LDL oxidation $(2,30)$. Also, plasma lutein is inversely correlated with age-related thickening of the coronary artery wall. Epidemiological studies also support the association of dietary lycopene intake and reduced risk of cardiovascular diseases (31).

The antioxidant activity of carotenoids has been suggested to decrease risk of cancer. However, carotenoids also have the potential to act as pro-oxidants. For example, chronic supplementation of high dose of BC to smokers was associated with increased risk of lung cancer for individuals also ingesting high alcohol $(9,10)$. The mechanism for the pro-oxidant effects observed at high carotenoid concentrations have yet to be fully established.

\subsubsection{Cell signaling and gene transcription}

Carotenoids influence cell proliferation, growth factor signaling, cell cycling, cell differentiation and gap junctional communication (GJC). For example, LYC and tocopherol inhibited growth of the prostate cancer cell lines DU-145 and PC-3 (36). Similarly, AC inhibited growth of GOTO human neuroblastoma cells (35). LYC also inhibited growth of mammary cancer cell by suppressing IGF-1 receptor signaling and delaying cell cycle progression (33). Such delayed cell cycle progression in response to LYC was also observed in leukemic, endometrial, lung and prostate cancer cell lines $(32,48)$. LYC also down-regulates cyclin D levels, a major growth factor sensor and a known oncogene (34). LYC in combination with retinoic acid or $1,25(\mathrm{OH})_{2} \mathrm{D}_{3}$ inhibited 
growth of tumor cell lines synergistically (32), suggesting LYC or its metabolites may interact with members of the nuclear receptor super-family. Carotenoids, such as BC may also be involved in the regulation of genes which are involved in apoptosis of cancer cells, such as Bcl-2 and Bax (49).

Gap junctions are water filled channels that link the cytoplasm of adjacent cells to facilitate chemical communication. Low molecular weight hydrophilic molecules that pass through these channels affect cell growth, differentiation and apoptosis. Nontransformed cells are contact-inhibited and have functional gap junctions. Dysfunctional GJC has been found for most cancer cells lacking contact-inhibition. It is interesting that carotenoids can stimulate GJC. Retinoids and some carotenoids have been shown to upregulate expression of connexin 43 ( $\mathrm{Cx} 43)$, a component of gap junction structure in non-transformed human and murine fibroblasts and keratinocytes (50). The mechanism of carotenoid induced upregulation of $\mathrm{Cx} 43$ remains unknown. It was recently reported that retinoids and nonvitamin A carotenoids stimulate $\mathrm{Cx} 43$ synthesis via different signaling pathways (40).

Carotenoids and their metabolites also have been suggested to regulate xenobiotic and other orphan nuclear receptors to modulate expression of phase I and phase II metabolizing enzymes (41). Cleavage products of BC and LYC have been shown to act as strong inhibitors of AP-1 transcriptional activity, and thus, inhibit its activation by growth factors, cytokines and UV radiation $(33,38)$. 


\subsection{Absorption and metabolism}

Because animals and human do not synthesize carotenoids de novo, they obtain these health promoting compounds from diets. Primary sources of carotenoids in the human diet include carrots (AC, BC), dark-green leafy vegetables (LUT, BC), tomatoes and watermelon (LYC), as well as mangos, oranges and papayas (CTX). Carotenoids are also relatively abundant in some foods of animal origin, such as dairy products including cheese and butter (BC), egg yolk (LUT), and certain foods of aquatic origin, such as shrimp, lobster, and salmon (AST).

Carotenoids are regarded as safe food colorants and are used in the form of plant extracts or as synthetic components in a variety of food products. Table 2.2 summarizes common fruits and vegetables rich in carotenoids consumed in US. The mean/median daily dietary intake of, BC, AC, CTX, LYC and LUT (+ZEA) are 2.15-2.62mg, 0.39mg, 0.12-0.14 mg, 1.6-1.7 $\mathrm{mg}$ and $2.0-2.3 \mathrm{mg}$, respectively (51).

Because carotenoids are lipophilic compounds, their digestion, absorption and transport are closely related to that of other dietary lipids. Carotenoids must be released from the food matrix, dissolved in oil droplets of chyme and then partitioned into mixed micelles for uptake by enterocytes. Pro-vitamin A carotenoids are partially processed to $\mathrm{RE}$ and both carotenoids and RE are incorporated into nascent chylomicrons prior to secretion into lymph (Figure 2.2) (52). A more detailed consideration of this pathway follows. 


\begin{tabular}{|c|c|c|c|c|c|}
\hline \multirow[t]{2}{*}{ Food } & \multicolumn{5}{|c|}{$\mu \mathrm{g} / 100 \mathrm{~g}$ edible portion } \\
\hline & $\alpha$-carotene & $\beta$-carotene & $\beta$-cryptoxanthin & $\begin{array}{r}\text { lutein }+ \\
\text { zeaxanthin }\end{array}$ & lycopene \\
\hline Apricots & 0 & 2,554 & 0 & 0 & 5 \\
\hline Beet greens & 5 & 3,405 & 0 & 0 & 0 \\
\hline Broccoli & 1 & 779 & 0 & 2,445 & 0 \\
\hline Brussels sprouts & 6 & 450 & 0 & 1,590 & 0 \\
\hline $\begin{array}{l}\text { Carrot A-plus } \\
\text { cultivar }\end{array}$ & 10,650 & 18,250 & 0 & 0 & 0 \\
\hline Carrots, baby & 4,425 & 7,275 & 0 & 358 & 0 \\
\hline Carrots & 4,649 & 8,836 & 0 & 0 & 0 \\
\hline Chard, swiss & 49 & 3,954 & 0 & 0 & 0 \\
\hline $\begin{array}{l}\text { Chrysanthemum, } \\
\text { garland }\end{array}$ & 0 & 1,320 & 24 & 0 & 0 \\
\hline Cilantro & 72 & 3,440 & 404 & 0 & 0 \\
\hline Collards & 238 & 3,323 & 80 & 0 & 0 \\
\hline $\begin{array}{l}\text { Corn, sweet, } \\
\text { yellow (cooked) }\end{array}$ & 0 & 133 & 0 & 1,800 & 0 \\
\hline Grape leaves & 0 & 16,194 & 4 & 0 & 0 \\
\hline $\begin{array}{l}\text { Greens, } \\
\text { fiddlehead ferns }\end{array}$ & 331 & 2,040 & 0 & 0 & 0 \\
\hline Kale & 0 & 9,226 & 0 & 39,550 & 0 \\
\hline $\begin{array}{l}\text { Lettuce, cos or } \\
\text { romaine }\end{array}$ & 0 & 1,272 & 0 & 2,635 & 0 \\
\hline Mangos & 17 & 445 & 11 & 0 & 0 \\
\hline
\end{tabular}

Continued

Table 2.2: Carotenoid content of common foods ( $\mu \mathrm{g} / 100 \mathrm{~g}$ editble portion). (data are from USDA carotenoid database for U.S. food- 1998) 
Table 2.2 continued

\begin{tabular}{|c|c|c|c|c|c|}
\hline $\begin{array}{l}\text { Melons, } \\
\text { cantaloupe }\end{array}$ & 27 & 1,595 & 0 & 40 & 0 \\
\hline Oranges & 16 & 51 & 122 & 187 & 0 \\
\hline Papayas & 0 & 276 & 761 & 75 & 0 \\
\hline Peaches & 1 & 97 & 24 & 57 & 0 \\
\hline Peas, green & 19 & 485 & 0 & 0 & 0 \\
\hline $\begin{array}{l}\text { Peppers, sweet, } \\
\text { red }\end{array}$ & 59 & 2,379 & 2,205 & 0 & 0 \\
\hline $\begin{array}{l}\text { Persimmons, } \\
\text { Japanese }\end{array}$ & 0 & 253 & 1,447 & 834 & 0 \\
\hline Spearmint, fresh & 0 & 2,133 & 0 & 0 & 0 \\
\hline Spinach & 0 & 5,597 & 0 & 11,938 & 0 \\
\hline $\begin{array}{l}\text { Squash, summer, } \\
\text { zucchini, } \\
\text { includes skin, } \\
\text { raw }\end{array}$ & 0 & 410 & 0 & 2,215 & 0 \\
\hline $\begin{array}{l}\text { Squash, winter, } \\
\text { butternut, raw }\end{array}$ & 834 & 4,226 & 820 & 0 & 0 \\
\hline $\begin{array}{l}\text { Tangerines, } \\
\text { (mandarin } \\
\text { oranges) }\end{array}$ & 14 & 71 & 485 & 243 & 0 \\
\hline $\begin{array}{l}\text { Tomatoes, red, } \\
\text { ripe, raw, year } \\
\text { round average }\end{array}$ & 112 & 393 & 0 & 130 & 3,025 \\
\hline Watermelon & 0 & 295 & 103 & 17 & 4,868 \\
\hline
\end{tabular}




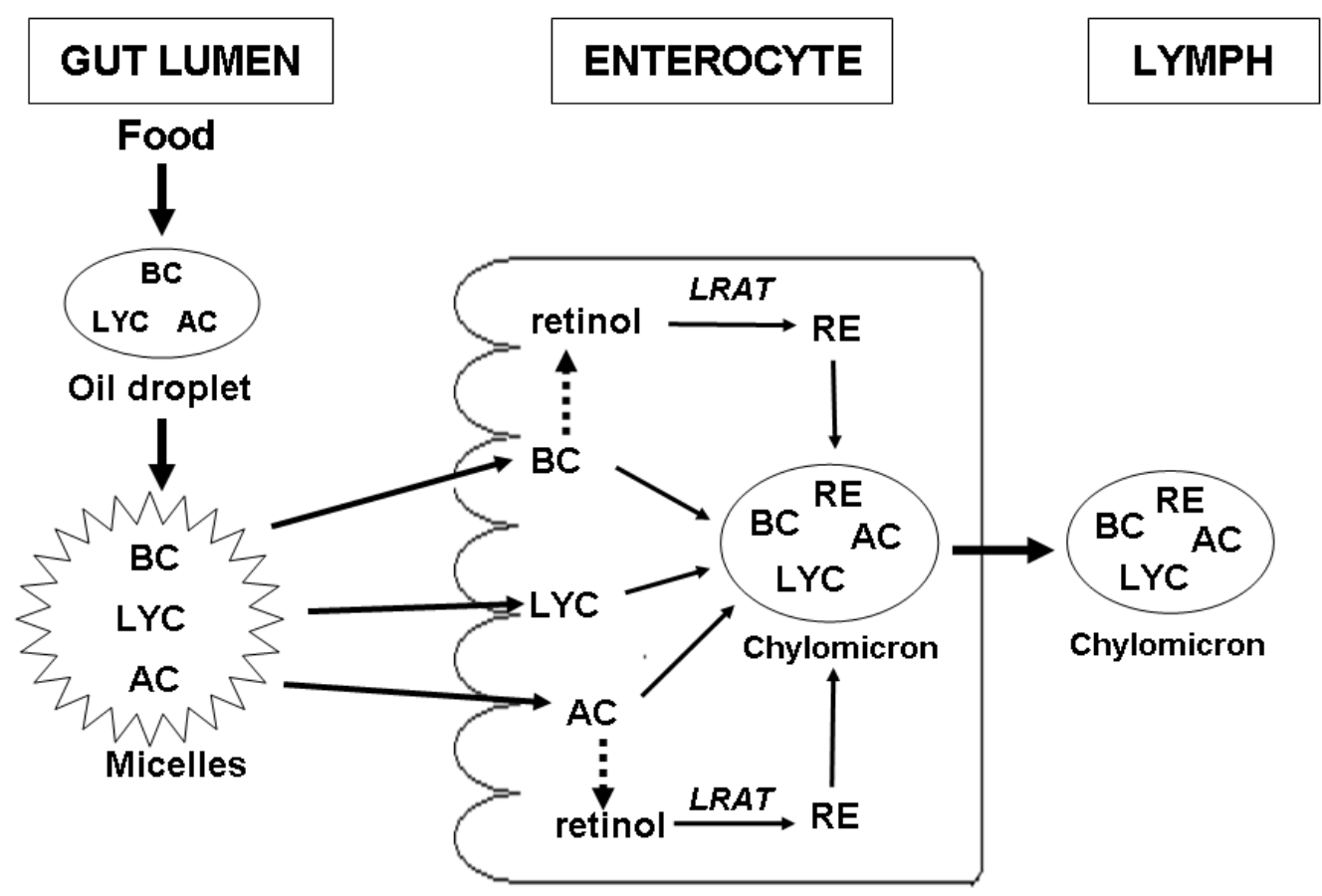

Figure 2.2: Digestion and absorption of carotenoids (133) 
Digestion is initiated in the oral cavity where the food is mechanically degraded by chewing and lubricated with saliva. Starch in foods is partially hydrolyzed by catalysis of $\alpha$-amylase in saliva. This begins the release of carotenoids from starch - rich food matrices, such as the food matrix in rice, cassava, sweet potato and corn (53). Within the gastric lumen, pepsin, hydrochloric acid $(\mathrm{HCl})$ and gastric lipases mix with ingested foods and further degrade the food matrix to mediate release of carotenoids from food matrix for dissolution in oil droplets within the chyme. Gastric lipase partially hydrolyzes TG to diacylglycerol and free fatty acids, which are emulsifiers for continued digestion of oil droplets. Polar carotenoids (e.g., LUT) tend to be distributed at the surface of the oil droplets, whereas nonpolar carotenoids (e.g., BC) are located in the core (54).

During the small intestinal phase of digestion, lipases degrade oil droplets to much smaller particles in the presence of bile salts (55). This activity is associated with conversion of triglycerides, phospholipids, cholesterol esters, RE and carotenoid esters to free fatty acids plus monoacylglycerols, lyso-phospholipids, free cholesterol, retinol and free carotenoids, respectively. These compounds are "solubilized" within micelles that diffuse across the unstirred water layer to deliver carotenoids and other lipophilic compounds to the apical surface of intestinal mucosal cells. The fraction of carotenoids transferred from the food matrix to mixed micelles during digestion is referred to as bioaccessibility (56). Early studies using intestine perfusion suggested that uptake of micellarized BC by intestinal epithelium is affected by factors such as length and saturation of fatty acids, $\mathrm{pH}$, and bile salt composition $(54,57)$. 
Carotenoid uptake from the mixed micelles by intestinal epithelium traditionally has been considered to occur by passive diffusion $(14,58)$. However, human studies showed that the absorption of LYC is saturable (59). Also, class B scavenger receptors type 1 (SR-B1) on mouse intestinal brush border membrane were shown to participate in the uptake of BC and cholesterol with SR-BI being essential for BC absorption (60). LUT transport was shown to partially require SR-B1 in Caco-2 TC-7 cells (61). Also, decreased carotenoid transport was associated with down-regulated expression of lipid transporters SR-B1, Niemann-Pick C1 Like 1 (NPC1L1) and ATP binding cassette transporter 1(ABCA1) in Caco-2 cells (62). Collectively, these data suggest that intestinal carotenoid uptake is a facilitated process and SR-B1 is required for the transport of some carotenoids.

A portion of the pro-vitamin A carotenoids such as $\mathrm{AC}$ and $\mathrm{BC}$ are cleaved by $\mathrm{BCO} 1$ generating retinal in the intestinal mucosal cells. Retinal is reduced to retinol and esterified by LRAT. Xanthophylls are not esterified in enterocytes despite the presence of hydroxyl groups. Intact carotenoids and RE are incorporated into chylomicrons and secreted into lymph. Chylomicrons are converted to remnants by lipoprotein lipase and such remnants are endocytosed by liver. In the liver, carotenoids can be stored intact, or converted to vitamin A, or re-secreted into circulation in very low density (VLDL), low density (LDL) and high density (HDL) lipoproteins for transport to peripheral tissues (63). LDL is the primary transporter of carotenes, whereas HDL is the primary transporter of xanthophylls. Different carotenoids selectively accumulate in tissues expressing a high density of LDL receptors. These tissues include adrenals, testes, liver, 
adipose tissue and kidney. Distribution of different carotenoids among tissues differs. For example, LUT and ZEA accumulate in macula region of retina, and LYC accumulates in prostate tissues $(64,65)$. Recent studies showed that HDL is critical for LUT and ZEA transport into the retina (63). The basis for selective accumulation of carotenoids in different tissues remains unclear.

\subsection{Factors affecting bioavailability}

Bioavailability refers to the fraction of ingested carotenoid transferred from food matrix to target tissues where it can be stored or utilized (66). The bioavailability of carotenoids has been shown to be affected by many factors as summarized in Table $\mathbf{2 . 3}$ and discussed below $(52,57,67)$.

\subsubsection{Physicochemical properties of carotenoids}

Carotenoids in foods may exist in the crystalline or solubilized state. Obviously, the bioavailability of carotenoids solubilized in oil droplets exceeds that of crystals since the solubilization in the droplets facilitates transfer to micelles (68). Carotenoid speciation also affects bioavailability. For instance, xanthophylls appear to have relatively higher bioavailability than carotenes (69). Since xanthophylls are more hydrophilic than carotenes, they are located at the surface of oil droplets with ready access to mixed micelles and more readily partitioned into micelles than carotenes (68, 70). Xanthophylls often are present as esters in fruits and vegetables. The esters are very 


\section{Physicochemical Properties of Carotenoids}

- Carotenoid speciation (e.g., xanthophylls vs. carotenes)

- Crystals vs. dissolved in oil droplets

- Free carotenoids vs. esters vs. protein bound

- All-trans vs. cis-isomers

\section{Food matrix and processing}

- Type of plant foods (eg. fruits vs. vegetables)

- Leaf vs. seeds vs. flowers

- Subcellular localization in plants

O (chromoplasts vs. chloroplasts vs. amyloplasts)

- Supplements vs. natural foods

- Food processing

○ Fresh vs. processed foods

○ Particle size (whole vs. chopped vs. pureed)

○ Processing methods

(grinding, juicing, cooking and fermentation)

\section{Interactions with other dietary components}

- Fiber, protein, lipids, phytosterols and other carotenoids

- Digestable vs. undigestable lipids

\section{Characteristics of subjects}

- Gut health

- Nutritional status

- Physiological status

- Genotype

Table 2.3: Factors affecting bioavailability of carotenoids (133) 
hydrophobic and require hydrolysis to the free form during digestion for efficient micellarization and uptake by enterocytes (71). Similarly, binding of carotenoids with plant proteins likely affects transfer of carotenoids to oil droplets (72). Isomeric structure can also affect bioavailability. For example, LYC is present in food sources mainly as all-trans form (79-91\%), whereas more than 50\% of LYC exists as cis-isomers in human serum and tissues (73). There is some evidence that pre-absorptive processes at least contribute to this phenomenon. These include isomerization in the acidic environment during digestion, and greater micellarization of cis-isomers of LYC (74-76). In contrast, increased consumption of cis-isomers of BC was not correlated with increase in these isomers in circulation (77-79), despite the greater micellarization of 9-cis-BC (80). You et al. found that orally administered 9-cis-BC was poorly absorbed but partially converted to all-trans BC prior to appearance in plasma (81). During et al. observed that the extent of transport of all-trans BC (11\%) was greater than those of 9-cis and 13-cis BC by Caco-2 human intestinal cells (2-3\%) (82), suggesting preferential absorption of all-trans $\mathrm{BC}$ by small intestine compared to the cis isomers.

\subsubsection{Food matrix and processing}

Carotenoids must be released from food matrix before they can be emulsified, micellarized and absorbed. Therefore, the food matrix has great impact on bioavailability. For example, carotenoids in oil-based supplements are better absorbed than carotenoids from vegetables $(69,83,84)$. It was also reported that the absorption of $\mathrm{BC}$ from carrots is more efficient than from leafy green vegetables $(56,81)$. 
Food processing can enhance bioavailability of carotenoids by altering the food matrix. This is due to disruption of plant cell walls and the linkages between the carotenoids and protein or fiber, dissolution of the crystalline carotenoids in oil droplets, and increasing surface area for greater access of hydrolytic enzymes and bile salts to oil droplets during digestion $(81,84-87)$. Thermal processing may also induce isomerization of some carotenoids which may affect bioavailability as described above.

\subsubsection{Interactions with other dietary components}

It has been demonstrated that various components in foods and meals can promote or inhibit carotenoid bioavailability. The association of carotenoids with protein may decrease absorption (88). Dietary fibers (citrus pectin, guar, alginate cellulose and wheat bran) have been reported to reduce absorption of carotenoids (89-91). This is likely due to binding of bile salts to fiber to inhibit efficient formation of micelles. Sucrose polyester and plant sterols also decrease micellarization of the hydrophobic compounds by interacting to form hydrophilic cores that are not subject to degradation by lipases $(92,93)$. Although phospholipids are important emulsifiers of dietary lipids in the digestive tract, the presence of phosphatidylcholine (PC) in mixed micelles inhibits the uptake of carotenoids by human intestinal Caco-2 cells and mice, possibly by shifting the equilibrium for partitioning of carotenoids into the micellar phase $(94,95)$. The influence of TG on carotenoid bioavailability will be summarized in details in the next section.

Several investigations have reported interactions between carotenoids, although these results remain controversial. For example, BC was reported to inhibit LUT 
absorption (84), and LUT decreased BC absorption in another study (96). It was reported that lutein, BC and LYC from vegetables were better absorbed when a single vegetable was ingested as compared to ingesting a second carotenoid-rich vegetable or carotenoid supplement. The mechanisms for pre-absorptive interactions between carotenoids remain unclear. Competition for micellarization, uptake by enterocytes and incorporation into chylomicrons have all been suggested (97). Also, dietary vitamin A intake results in more efficient absorption of provitamin A cartoenoids likely due to decreased cleavage of by BC mono-oxygenase (98).

\subsubsection{Health status and genotype of hosts}

The absorption of carotenoids is modulated by the health status of individuals. Abnormalities in the composition and activity of digestive enzymes in the gut lumen, as well as pathological changes in morphological and functional integrity of the absorptive epithelium, may affect the efficiency of absorption. For example, increased gastric $\mathrm{pH}$ decreases BC absorption (99). Diseases (cholestasis, biliary cirrhosis, pancreatic insufficiency) that cause fat malabsorption also inhibit carotenoid absorption (11). Moreover, intestinal parasitism impairs carotenoid absorption (100).

Nutritional status is another important factor affecting carotenoid absorption. Vitamin A deficiency is often associated with deficiency of other nutrients. For example, plasma vitamin A response induced by BC supplementation was lower in protein deficient rats than in normal rats (101). Severe vitamin A deficiency compromises the integrity of epithelial barriers, which induces malabsorption of pro-vitamin A carotenoids. Finally, BCO1 activity was positively associated with iron content in rat 
tissues and inversely associated with vitamin A status (102). Polymorphisms in genes also likely affect the absorption and bioconversion of carotenoids. The gene products involved in digestion, intestinal cell uptake, bioconversion of carotenoids, as well as synthesis and secretion of chylomicrons, have the potential to affect carotenoid bioavailability. Specific examples of such genetic effects have not been reported.

\subsection{Influence of dietary lipids the absorption of carotenoids}

One of the earliest studies from Jayarajan and associates reported that dietary fat enhanced carotenoid absorption (103). Subsequent animal and human studies have confirmed this observation and further demonstrated that fat is likely the most important dietary promoter of carotenoid absorption (104-107). Moreover, several studies have demonstrated that the amount and composition of fat also can influence carotenoid bioavailability (Table 2.4). Several mechanisms are likely responsible for this phenomenon. Dietary fat may facilitate the release of carotenoids from the food matrix by serving as a sink for hydrophobic compounds. Dietary fat also stimulates the secretion of bile and pancreatic enzymes, which increases formation of mixed micelles in the small intestine. Moreover, the synthesis and secretion of chylomicrons by enterocytes is increased by dietary fat. Dietary fatty acids likely affect cleavage of provitamin A carotenoids to retinal. The promoter region of $\mathrm{BCO} 1$ gene contains a piece of cis element for binding of PPAR- $\gamma(167)$. 


\begin{tabular}{|c|c|c|c|c|c|}
\hline $\begin{array}{l}\text { Animal } \\
\text { /subject }\end{array}$ & Test material & Carotenoids & $\begin{array}{l}\text { Test period } \\
\text { int of dietary fat }\end{array}$ & Effect of oil on absorption & Ref. \\
\hline rats & lipid emulsion & $\mathrm{CTX}^{1}$ & infusion for $12 \mathrm{~h}$ & olive oil $\uparrow \mathrm{CTX}$ absorption & $(104)$ \\
\hline human & cooked tomatoes & LYC & $1 \mathrm{meal} / \mathrm{d}, 5 \mathrm{~d}$ & olive oil $\uparrow$ LYC absorption & $(108)$ \\
\hline human & supplement in oil & LUTE, AC+BC & $7 d$ & LUTE requires more fat than $\mathrm{AC}+\mathrm{BC}$ & $(107)$ \\
\hline human & salad with dressing & $\mathrm{AC}, \mathrm{BC}, \mathrm{LYC}$ & single meal & full fat $(28 \mathrm{~g})>$ low fat $(6 \mathrm{~g})>$ no fat & (14) \\
\hline human & salad, salsa & $\begin{array}{l}\text { LUT, AC, BC, } \\
\text { LYC }\end{array}$ & single meal & $\begin{array}{l}\text { avocado fruits }(150 \mathrm{~g})=\text { avocado } \\
\text { oi }(20 \mathrm{~g}) 1>\text { no oil }\end{array}$ & $(15)$ \\
\hline \multicolumn{6}{|c|}{ Type of fat } \\
\hline rat & lipid emulsion & LYC, AST & infusion for $12 \mathrm{~h}$ & olive oil > corn oil $(3 \% \mathrm{wt} / \mathrm{vol})$ & $(108)$ \\
\hline rats & Green leaf vegetables & LUT, ZEA & Single meal & $\begin{array}{l}\text { LUT+ ZEA postprandial plasma } \\
\text { response olive oil }>\text { sunflower oil, } \\
\text { groundnut oil }\end{array}$ & (109) \\
\hline human & pasta + tomato sauce & LYC & two meals & $\begin{array}{l}\text { high phenolic olive oil >low phenolic } \\
\text { olive oil } \\
>\text { high-oleic safflower oil }>\text { safflower } \\
\text { oil }(25 \mathrm{ml})\end{array}$ & $(110)$ \\
\hline human & BC-supplemented meal & $\mathrm{BC}$ & single meal & beef tallow $>$ sunflower oil $(60 \mathrm{~g})$ & (111) \\
\hline human & BC-supplemented meal & $\mathrm{BC}, \mathrm{RP}$ & single meal & LCT > MCT (40g) & $(105)$ \\
\hline
\end{tabular}

* CTX: cryptoxanthin; AC: $\alpha$-carotene; BC: $\beta$-carotene; LUT: lutein; LUTE: lutein esters; ZEA: zeaxanthin; AST: astaxanthin; LYC: lycopene; RP: retinyl palmitate.

Table 2.4: Influences of dietary fat on carotenoid absorption 
The optimal amount of dietary fat for maximum absorption of carotenoids from a meal remains controversial. It has been reported that at least $5 \mathrm{~g}$ fat in a meal was required for carotenoid absorption (103). Unlu et al. showed that the addition of avocado or avocado oil to a vegetable salad meal significantly increased the absorption of carotenoids (LUT, BC, AC and LYC). Brown et al. recently reported that absorption of $\mathrm{AC}, \mathrm{BC}$ and LYC from salad with dressing containing $28 \mathrm{~g}$ canola oil was greater than salad with dressing containing only $6 \mathrm{~g}$ canola oil (14). Xanthophylls exist as mono- and di-esters in many fruits and vegetables. Our laboratory recently showed that intestinal cell uptake of zeaxanthin from several digested vegetables is dependent on hydrolysis of ZEA esters by carboxyl ester lipase (CEL) (71). Ester cleavage is required for efficient micellarization and apical uptake of xanthophylls by Caco-2 human intestinal epithelial cells. Thus, fat-induced release of pancreatic enzymes including CEL is needed for conversion of the esters to free xanthophylls in the intestinal lumen. Several human studies have shown that the fatty acid composition (chain length and degree of unsaturation) of dietary TG can affect carotenoid bioavailability (Table 2.4). Borel and associates have shown that TG with long chain acyl groups increased the concentrations of $\mathrm{BC}$ and $\mathrm{RE}$ in the isolated chylomicrons from human plasma compared to the TG with medium chain length acyl groups (112). Dietary oils enriched in oleic acid enhanced postprandial plasma carotenoid response compared to the oils with saturated or polyunsaturated fatty acyl groups $(108,111)$. This is possibly due to oleate-mediated promotion of chylomicron assembly and secretion by small intestinal epithelium $(113,114)$, although the mechanisms of oleic acid promoting chylomicron 
secretion remain unclear. Recently, an in vitro study using human intestinal Caco-2 cells showed palmitic acid is more cytotoxic than oleic acid in part because the triglycerides enriched in palmitic acid tend to solidify and accumulate in lipid dense granules within cells at body temperature (115).

\subsection{Models for investigating pre-absorptive metabolisms of dietary carotenoids}

Digestion and absorption of carotenoids, as well as conversion of dietary carotenoids to vitamin $\mathrm{A}$, have been investigated in vivo and in vitro. The advantages and disadvantages of the various approaches are discussed in this section.

\subsubsection{In vivo models}

\subsubsection{Human studies}

Mass balance, gastrointestinal effluent measurement and plasma response to single and chronic administration of carotenoids have been used to investigate carotenoid bioavailability in human subjects. Improved physiological functions, such as vision, in subjects also have been used as indicators of the bioavailability of carotenoids from supplements or carotenoid-rich diet $(116,117)$. Mass balance techniques involve monitoring the change of carotenoid contents in gastrointestinal lumen or in feces after digestion $(118,119)$ for the noninvasive estimation of carotenoid absorption. Compared to metabolic balance studies, the measurement of intestinal effluent from subjects with ileostomy and gastrointestinal lavage and sampling methods provide more information about possible changes of carotenoids during digestion process (e.g., isomerization and hydrolysis of carotenoid esters) $(85,119-121)$. Such samples are likely to contain both 
ingested carotenoids retained in food matrix, absorbed carotenoids that have been secreted into gastrointestinal lumen with bile, retro-transported carotenoids transferred from the mucosal epithelium into the lumen, and carotenoids within cells sloughed from intestinal and colonic villi.

Plasma response techniques have been used more often to assess carotenoid bioavailability in recent studies. Human subjects ingest one or more doses of carotenoid supplements or carotenoid rich foods and the changes of plasma carotenoid level before and after ingestion are measured. Quantifying carotenoids in postprandial chylomicrons represents a more accurate approach to evaluate carotenoid bioavailability than simply measuring carotenoids in plasma (122). Subjects are often required to ingest low carotenoid diets for several weeks before the test to decrease endogenous carotenoids in plasma. The plasma response curve is used to estimate relative bioavailability. Stable isotope $\left({ }^{2} \mathrm{H}\right.$ and $\left.{ }^{13} \mathrm{C}\right)$ labeled carotenoids facilitate detection of trace amounts of carotenoids in plasma or the plasma TG-rich fractions, providing a more sensitive assessment of the absorption of ingested carotenoids and their cleavage products (87, 123-126). However, the high cost of the stable isotopes and mass spectrometry equipment limits the application of stable isotopes. To conclude, although direct evaluation of carotenoid absorption in human subjects represents the ideal standard for assessing bioavailability, human studies generally are expensive and labor intensive and limited in sampling tissues. 


\subsubsection{Animal models}

Animal models offer a number of advantages compared to human subjects for determining bioavailability of ingested compounds. These include the ability to induce dietary deficiencies and excesses, administer radioisotopes as tracers and collect tissues of interest. Mouse, rat, gerbil, ferret, preruminant calf, nonhuman primates, pig, chicken, dog, cat, reptiles and amphibians have been used to study carotenoid absorption, metabolism and function (127).

However, no animal model accurately mimics the absorption and metabolism of all carotenoids in humans. For example, enterocyte conversion of $\mathrm{BC}$ to vitamin $\mathrm{A}$ in rodent intestine is much more efficient than for humans. However, the rat is a useful model to study the consequences of vitamin A deficiency as dietary restriction of vitamin A and $\mathrm{BC}$ rapidly deplete hepatic vitamin A stores in rats. As with humans, $\mathrm{BC}$ can be absorbed intact by gerbils, ferrets and preruminant calves can absorb BC intact, although only gerbils and preruminant calves convert $\mathrm{BC}$ to vitamin A with efficiency similar to human. The high cost of maintaining calves limits their utility in research of carotenoids absorption and metabolism. Compared to other animal models, the gerbil represents a practical model (128-130).

Because no specific animal model completely mimics the absorption and metabolism of carotenoids in human, careful consideration of the specific application being studied merits critical consideration. 


\subsubsection{In vitro models}

In vitro models include simulated gastric and small intestinal digestive processes $(70,131)$, isolated intestinal cells and intestinal segments (132), and the brush-border and basolateral membrane vesicles (60). These models facilitate investigations of factors influencing digestive stability, micellarization and intestinal transport and bioconversion of carotenoids from foods and supplements. Our laboratory has developed a model that couples simulated gastric and small intestinal digestive processes with highly differentiated cultures of Caco-2 human intestinal cells (70)

\subsubsection{Simulated digestion}

Simulated digestion has been shown to become economical and efficient model to screen the bioaccessibility of carotenoids from fruits and vegetables, meals and supplements (133). The in vitro digestion procedure mimics conditions in the stomach and small intestine by exposing the food matrix to the $\mathrm{pH}$ and digestive enzymes at $\mathrm{pH}$ that characterizes each compartment. After completion of simulated gastric and small intestinal digestion, the resultant chyme is centrifuged to isolate the aqueous fraction before filtration through $0.22 \mu \mathrm{m}$ pore size filter to eliminate the microcrystalline aggregates to obtain the micellar fraction (70). An oral phase of digestion can be readily included with this procedure (53). Carboxyl ester lipase (CEL) can be readily added along with pancreatin to enhance lipolysis $(71,131)$. In this project, I used high speed centrifugation, but we recently showed that substitution of the more cost effective low speed centrifugation $(5,000 \mathrm{~g})$ for high speed centrifugation $(167,000 \mathrm{~g})$ did not alter the concentration of carotenoids in the micellar fraction (134). The advantages of the 
simulated digestion procedure include its relatively low cost, ability to modulate controlled digestive conditions, convenient sampling during the digestive process, and use of equipment present in most laboratories. These factors contribute to the potential for high throughput and adoption by many laboratories.

\subsubsection{Caco-2 intestinal cell model}

The Caco-2 human intestinal cell line is a polyclonal human intestinal cell line. It is the most widely used intestinal epithelial cell model to measure the uptake and secretion of compounds. Although it originates from a human colonic adrenocarcinoma, the cells spontaneously develop morphological and biochemical characteristics of enterocytes during differentiation. After $\sim 14 \mathrm{~d}$ of differentiation, the polarized cells form a monolayer by the linkage of tight junctions and desmosomes, that separate the apical and basolateral membrane. Caco-2 express the key enzymes and transporters for carotenoid and vitamin A uptake, transport and metabolism, including carboxyl ester lipase, LRAT, NPC1L1, ABCA1, and SR-B1. BCO1 activity is absent in the parental HTB37 Caco-2 cell line. However, TC-7, a monoclonal cell line isolated from Caco-2, expresses BCO1 activity and is utilized to study the conversion of BC to vitamin A in enterocytes (135).

The culture conditions are critical for the morphology and biochemical characteristics of Caco-2 cells. The cells require a minimum of 10-12 days postconfluency to differentiate to enterocyte-like state and 21-25 days for effective synthesis and secretion of lipoproteins. The assembly and secretion of the large and small chylomicrons require treatment of fatty acids, particularly oleic acid to simulate 
the postprandial conditions $(136,137)$. It was also reported that a low glucose supply in the culture media for 2 weeks enhanced the response of the Caco- 2 cells to oleic acid treatment and therefore secreted more chylomicrons (137). Sambuy et al. has reviewed the use of Caco-2 and factors influencing its functional characteristics (138).

In spite of many similarities, there are still some differences between Caco-2 and human small intestinal epithelial cells. One of the important differences is that Caco-2 cells predominantly use the glycerol 3-phosphate pathway for the synthesis of triacylglycerols, whereas the small intestinal epithelium uses the monoacylglycerol pathway (139). Recently, studies also showed that sn-2 monoacylglycerol stimulated Caco-2 to produce more TG, which suggests that Caco-2 may also use monoacylglycerol pathway to synthesize TG.

Caco-2 cell model has been used to study the apical uptake, metabolism and transepithelial transport of vitamins, minerals, amino acids, monosaccharide, fatty acids, and other dietary components, including carotenoids (140-146). Because of the high correlation between the efficiency of oral drug absorption and transepithelial transport through Caco-2 monolayer, Caco-2 is widely used for quick screening of transport and metabolism of new drugs. From 1985 to 2006, a total of 5764 research papers were published using Caco-2 cells as the cell model, which indicates the wide use of this model by nutritional, physiological and pharmacological researchers.

\subsubsection{The coupled simulated digestion / Caco-2 cell model}

Garrett et al. first coupled the simulated digestion model with highly differentiated cultures of Caco-2 cell to simulate the physiological conditions of both 


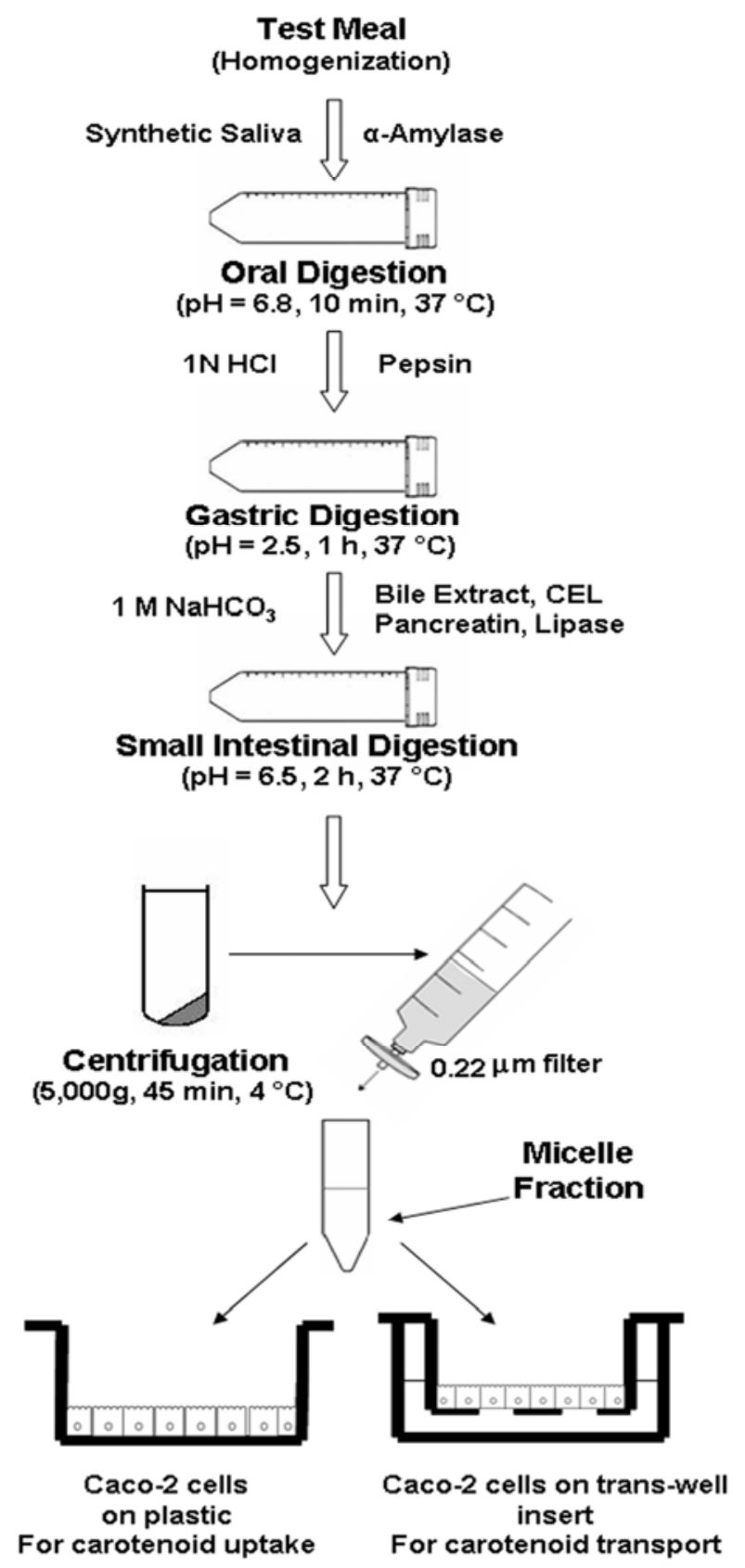

Figure 2.3: Graphical representation of coupled in vitro digestion/Caco-2 cell uptake model to assess carotenoid bioaccessibility (134). 
digestion and intestinal cell uptake processes (70). The procedure is shown in Figure 2.3. Caco- 2 cells can be treated with the mixed micelle fraction generated during the simulated digestion is diluted with culture media (usually 1:4 ratio). Cells can be grown on plastic dishes for compound accumulation experiment, or grown on membrane inserts to answer questions related to transepithelial transport of the compounds. The coupled simulated digestion / Caco-2 model is economical and high throughput for quick screening the relative bioaccessibility of carotenoids from fruits and vegetables, meals and supplements. Also, it facilitates evaluation of the impact of chemical speciation, food matrix, style of food processing, and various dietary factors on digestive stability, micellarization, and intestinal cell uptake and transport of carotenoids.

\subsection{Validation of in vitro bioaccessibility}

As a model, the simulated digestion/Caco- 2 cells has some limitations. First, the simulated digestion is a closed system, which does not respond to the amount and composition of the foods, that is, the $\mathrm{pH}$ and the concentrations of bile salts and digestive enzymes are constant during each digestion stage. Second, some enzymatic activities present in exocrine pancreas, such as CEL activity, are absent in the pancreatin used in the in vitro model. CEL is not generally added in our simulated digestion system because of its high cost. However, it can be used to address questions related to hydrolysis of xanthophyll esters (71). Similarly, oral phase is not generally included, although this phase can also be included when necessary (53). Large intestinal phase is usually absent and needs more exploration. The culture lacks goblet cells to secret 
mucin, and the effects of biofilms are also difficult to measure. Therefore, validation of the data from in vitro model by in vivo studies turns to be especially important.

Recently, Borel and associates validated the in vitro model by comparing micellarization during in vitro digestion with 1) human-derived bioaccessibility data and 2) bioavailability data from published human studies (147). They reported that bioaccessibility as determined by in vitro digestion is highly correlated $\left(\mathrm{R}^{2}=0.90, P<\right.$ 0.05) with data derived by sampling small intestinal luminal contents from human subjects fed carotenoid rich vegetables and bioavailability data from published human studies $\left(\mathrm{R}^{2}=0.98, P<0.001\right)$. This evidence proved that the bioaccessibility data generated from the in vitro model are reliable predictors of in vivo relative bioaccessibility of carotenoids. 


\title{
CHAPTER 3
}

\author{
IMPACT OF FATTY ACYL COMPOSITION AND \\ QUANTITY OF TRIGLYCERIDES ON
}

\section{BIOACCESSIBILITY OF DIETARY CAROTENOIDS}

Reproduced with permission from J.Agric Food. Chem. 2007, 55 (22), 8950-8957.

Copyright 2007 American Chemical Society 


\subsection{Introduction}

Many of the hundreds of carotenoids in nature are C40 compounds with 10-11 conjugated double bonds. Some of these compounds are often classified as carotenes (e.g., LYC; AC; and BC) and others as xanthophylls (e.g., LUT; ZEA; and CTX). Xanthophylls are more hydrophilic than carotenes due to the presence of hydroxyl and keto groups on one or both ionone rings. Among the many reported biological activities of carotenoids and their metabolites are the ability to quench singlet oxygen and reactive oxygen species, serve as precursors for vitamin A, modulate transcription of target genes, and enhance communication between adjacent cells via gap junctions $(2,24,31$, $48,148)$. In order to carry out such activities in tissues, dietary carotenoids must be bioavailable, i.e., transferred from the food matrix to target tissues. The bioavailability of carotenoids from a meal can be affected by numerous factors including chemical speciation, food matrix, styles of processing and cooking, interactions with other dietary compounds such as fiber, lipids, phytosterols and other carotenoids during digestion and absorption, gut health, nutritional status and other conditions that affect digestion and absorption processes (13).

Among dietary factors that influence bioavailability, co-ingestion of lipids appears to have the greatest impact on the absorption of ingested carotenoids. It was originally reported that 3-5 g of fat was required for absorption of $\mathrm{BC}$ from a meal (103, 107). Brown et al. recently reported that absorption of AC, BC and LYC from salad with dressing containing $28 \mathrm{~g}$ canola oil was greater than that containing only $6 \mathrm{~g}$ canola oil (14). Moreover, subjects who ingested a carotenoid - rich salad meal with either 
avocado oil alone or avocado fruit containing an equivalent amount of oil had greater plasma response to ingested carotenes compared to subjects who ingested a fat-free, carotenoid - rich salad meal (15). Several human studies also have shown that fatty acyl composition of TG can affect carotenoid absorption. Co-ingestion of a BC-supplement with beef tallow increased the level of BC in plasma TG-rich lipoproteins in human subjects to a greater extent than that with an equivalent amount of sunflower oil (111). Also, the amounts of $\mathrm{BC}$ and retinyl esters in the chylomicron fraction of plasma were greater when TG containing long chain fatty acyl groups was co-ingested with a salad meal by human subjects compared to TG with medium chain fatty acyl groups (112). Moreover, micellar oleic and eicosapentaenoic acid, but not linoleic acid, have been reported to enhance $\mathrm{BC}$ absorption and its cleavage into retinol in rats (149).

The absorption of carotenoids, like other lipophilic compounds, is characterized by a series of processes that include release from the food matrix and dissolution in oil droplets, lipase- and bile salt-dependent partitioning into mixed micelles for delivery to the apical mucosal surface for uptake by enterocytes, and incorporation of the intact compound or its esterified cleavage products into chylomicrons for secretion into lymph (52). Although the amount and physicochemical characteristics of dietary lipids likely affect one or more of these steps, specific mechanisms for the dietary lipid-carotenoid interaction have received limited attention.

We report here the results from investigations on the influence of amount and structure of TG on the bioaccessibility of carotenoids. Bioaccessibility refers to the efficiency of transfer of a carotenoid from food matrix to mixed micelles during 
digestion (147). Incorporation into mixed micelles is required for lipophilic compounds to be transported across the unstirred water layer for uptake by small intestinal epithelial cells. The first specific aim was to evaluate the influence of chain length and degree of unsaturation of acyl groups in TG and amount of TG on micellarization of carotenoids

from a typical western salad using simulated gastric and small intestinal digestion. The usefulness of this model as a positive predictor of carotenoid bioavailability in vivo has been established (147). The second aim was to examine the influence of TG fatty acyl chain length (c8:0 vs. c18:1) on intestinal cell uptake of carotenoids from micelles generated during simulated digestion.

\subsection{Materials and methods}

\subsubsection{Chemicals}

Unless indicated, all other chemicals were purchased from either Fisher Scientific (Norcross, GA) or Sigma-Aldrich (St Louis, MO). Lutein standard was a gift from Dr. Zoraida DeFreitas (Kemin Foods Inc., Des Moines, IA). TG with either cis-9, trans-11 conjugated linoleic acids (CLA) or trans-10, cis-12 CLA were purchased from Cognis (Cincinnati, OH). Dietary oils were purchased from a local grocery and fatty acyl composition of the dietary oils was determined by saponification followed by fatty acyl methylation in presence of $20 \%$ 1,1,3,3-tetramethylguanidine (TMG) in methanol (v/v), and analysis by Gas Chromatography (GC) (150). As expected, predominant fatty acids were c18:2(68.0\%) and c18:1(15.6\%) in safflower oil, c18:1(58.9\%) and c18:2(19.7\%) in canola oil, and c12:0(46.8\%), c14:0(19.8\%) and c16:0(10.3\%) in coconut oil. Caco-2 cells were purchased from American Type Culture Collection (ATCC, Manassas, VA). 


\subsubsection{Preparation of test meals}

A western - type salad was prepared to examine the effects of chain length and degree of unsaturation of fatty acyl groups in TG on micellarization of carotenoids during in vitro digestion. The salad contained the following carotenoid-rich vegetables and fruits: $20 \%$ spinach; $35 \%$ tomato; $25 \%$ carrot; $10 \%$ romaine lettuce; and, $10 \%$ orange pepper $(\mathrm{w} / \mathrm{w})$. The salad was homogenized with a KitchenAid hand mixer until puréed at room temperature. Aliquots were transferred to screw cap polypropylene tubes and stored under nitrogen gas at $-80^{\circ} \mathrm{C}$. Carotenoid content of the frozen salad purée was determined monthly and remained stable (i.e., equivalent to fresh prepared purée) for at least 6 months. Lipids were extracted from $1 \mathrm{~g}$ salad purée with $2 \mathrm{~mL}$ chloroform and 1 mL methanol, saponified, and methylated with 20\% TMG in methanol to determine fatty acyl composition by GC $(150,151)$. Fatty acids accounted for $0.1 \%$ of the wet weight of salad purée and c18:2 (29\%) and c18:3 (37\%) were predominant.

To investigate the effect of fatty acyl chain length on the uptake of carotenoids presented in micelles by Caco- 2 cells, the test meal contained a mixture of puréed spinach $(0.6 \mathrm{~g})$ and carrot $(1.0 \mathrm{~g})$ with either $2.5 \%(\mathrm{v} / \mathrm{w})$ triolein or trioctanoin. These vegetables were used instead of the salad to generate micelles containing higher amounts of LUT, BC and AC for the experiment with Caco-2 cells described below.

\subsubsection{In vitro digestion}

The general procedure for the simulated gastric and small intestinal digestion was based on the method described previously with modifications $(70,131)$. The salad purée ( $3 \mathrm{~g}$ ) with indicated quantities of test lipids was subjected to simulated digestion. 
The purée was diluted with $27 \mathrm{~mL}$ saline (120 mM sodium chloride). The $\mathrm{pH}$ for gastric digestion was adjusted to $3.0 \pm 0.1$ instead of $2.0 \pm 0.1,40 \mathrm{mg}$ pepsin in $2 \mathrm{~mL} \mathrm{HCl}(0.1$ M) was added, and the total volume was increased to $40 \mathrm{~mL}$ with saline. For small intestinal digestion, porcine pancreatic lipase (Sigma, L3126) was added along with porcine pancreatin and bile extract to facilitate greater hydrolysis of triglycerides in the test meal. Final concentrations of the bile extract, pancreatin and pancreatic lipase for small intestinal digestion (50 mL total volume) were $2.4,0.4$ and $0.2 \mathrm{mg} / \mathrm{mL}$ respectively.

After completing the simulated gastric and small intestinal phases of digestion, an aliquot (10 mL) of chyme was centrifuged (Type 50 Ti rotor, Beckman Model L7-65) at $167,000 \mathrm{~g}$ at $4^{\circ} \mathrm{C}$ for $20 \mathrm{~min}$ to separate the aqueous fraction containing mixed micelles from residual solids and oil droplets. The aqueous fraction was filtered (Millex ${ }^{\circledR}$ GP, 33 $\mathrm{mm}$ diameter, $0.22 \mu \mathrm{m}$ pore size, Millipore) to prepare micelle fraction. Chyme and the micelle fraction were blanketed with nitrogen gas, stored at $-20{ }^{\circ} \mathrm{C}$ and analyzed within a week.

\subsubsection{Uptake of carotenoids by Caco-2 human intestinal cells}

Details regarding the maintenance of cultures of Caco-2 cells (HTB-37, ATCC) have been described previously (152). One modification for the present experiment was the substitution of HEPES $(15 \mathrm{mmol} / \mathrm{L})$ by PIPES as a buffer in the DMEM to maintain $\mathrm{pH}$ of the medium at 6.8 instead of 7.4. For experiments, cultures of Caco-2 at passages 25-26 were seeded in six well dishes (Falcon, Morristown, TN) at $5 \times 10^{4}$ cells $/ \mathrm{cm}^{2}$ and were used between 11 to $13 \mathrm{~d}$ post confluency. 
Mixed micelles with carotenoids for addition to cultures of Caco-2 cells were generated by digestion of a purée of spinach $(0.6 \mathrm{~g})$ and carrot $(1 \mathrm{~g})$ containing either triolein or trioctanoin $(2.5 \%, \mathrm{v} / \mathrm{w})$. The micelle fraction contained LUT, AC and BC. To prepare filtered aqueous fraction with different concentrations of these three carotenoids but similar amounts of micelles, the micelles produced by digesting salad purée with either triolein or trioctanoin were diluted 4:0, 3:1, 1:1, 1:3 and $0: 4(\mathrm{v} / \mathrm{v})$ with carotenoidfree micelles generated by digesting the same lipid without salad purée. Appropriately diluted micelle fractions then were mixed with 3 volumes of basal DMEM with Lglutamine (2mmol/L, GIBCO) and non-essential amino acids (10mL/L, GIBCO). Caco2 cells were harvested after $4 \mathrm{~h}$ exposure to media with the various concentrations of carotenoids as reported by Chitchumroonchokchai et al. (152). Microscopic examination prior to harvesting suggested that monolayers remained intact and gross cell morphology was not affected by test treatments. Similarly, mean cell protein content per well was independent of treatment.

\subsubsection{Extraction of carotenoids from salad purée, chyme and micellar fraction}

The salad purée was thawed, homogenized and $2 \mathrm{~g}$ purée was mixed with $100 \mu \mathrm{g}$ apo-8'- $\beta$-carotenal (internal standard) in $1 \mathrm{~mL}$ petroleum ether, $2 \mathrm{~g}$ Celite ${ }^{\circledR}, 1 \mathrm{~g}$ calcium carbonate and $6 \mathrm{ml}$ methanol. Then $50 \mathrm{~mL}$ cold $\left(4^{\circ} \mathrm{C}\right)$ petroleum ether/acetone $(3: 1)$ was added and the mixture homogenized for $60 \mathrm{sec}$ (Ultra-Turrax ${ }^{\circledR}$ tissumizer, Janke \& Kunkel, IKA Equipments). The homogenate was filtered $(2.5 \mu \mathrm{m}$ pore size, Whatman, Grade 42) and the residue was repeatedly extracted 3 - 4 times until both residue and filtrate were colorless. After extraction, combined filtrates were saponified in dark with 
$50 \mathrm{~mL}$ of $30 \%(\mathrm{w} / \mathrm{v})$ potassium hydroxide in methanol for $30 \mathrm{~min}$. The organic fraction was washed with $10 \mathrm{ml}$ of deionized water twice and separated from the aqueous fraction using a separatory funnel. The organic fraction was then passed though anhydrous sodium sulfate to adsorb residual water and diluted to $100 \mathrm{~mL}$ with petroleum ether. Aliquots $(2 \mathrm{~mL})$ were dried under a stream of nitrogen and stored at $-20^{\circ} \mathrm{C}$. Recovery of apo-8'- $\beta$-carotenal from the purée exceeded $90 \%$.

Carotenoids were also extracted from chyme and micelle fraction as described previously (152). Briefly, $1 \mu \mathrm{g}$ of apo-8'- $\beta$-carotenal in $100 \mu$ l petroleum ether was added to either $2 \mathrm{ml}$ of chyme or micelle fraction as an internal standard and carotenoids were extracted three times with petroleum ether:acetone $(2: 1)$ containing $0.1 \%(\mathrm{w} / \mathrm{v})$ of butylated hydroxytoluene (BHT). Organic fractions were combined and dried under a stream of nitrogen gas for HPLC analysis. Recovery of apo-8'- $\beta$-carotenal from chyme and micelle fraction exceeded $88 \%$.

\subsubsection{Carotenoid analysis by HPLC}

Dried extracts were reconstituted in $1 \mathrm{~mL}$ ethyl acetate/methanol (1:1) and analyzed by HPLC (Waters 2695 separation module with a Waters 2996 photodiode array detector). Carotenoids were separated by using a C18 reverse phase column (Vydac, 201TP54, 4.6mm x 250mm, particle size $5 \mu \mathrm{m}$ ) that was protected by a NovaPak C18 guard column (Waters Corporation, Milford, MA). Analytes were eluted from the column with differing proportions of methanol containing $2 \%$ water with $1 \mathrm{M}$ ammonium acetate (solvent A) and ethyl acetate (solvent B). The solvent gradient was as follows and passed through the column at a flow rate of $1 \mathrm{~mL} / \mathrm{min}: 0-5 \mathrm{~min}, 100 \% \mathrm{~A}$; 
6-25 $\mathrm{min}, 100 \%$ to $80 \% \mathrm{~A} ; 25-30 \mathrm{~min}, 80 \%$ to $100 \% \mathrm{~A} ; 30-35 \mathrm{~min}, 100 \% \mathrm{~A}$.

Carotenoids were detected at $450 \mathrm{~nm}$. Retention time and absorption spectra of pure standards were used to identify and quantify LUT, ZEA, AC, BC and LYC. Because the chromatographic procedure failed to completely separate LUT and ZEA, total area of the two peaks was determined and results are expressed as LUT (+ ZEA) for salad, chyme and aqueous fraction.

\subsubsection{Miscellaneous assays}

Cell protein was determined using bicinchoninic acid assay (BCA; Pierce, Rockford, IL) with bovine serum albumin as a standard.

\subsubsection{Statistical Analysis}

Statistical analysis was performed using SPSS/Win 14.0. The efficiency of micellarization was calculated for each carotenoid in each meal sample. Data are expressed as means \pm SEM. Significant differences for effects of amount and type of lipids were tested by one-way ANOVA followed by Tukey's post hoc test. A minimum of 3 observations $(n=3-6)$ were made to determine whether there were significant differences between groups. The differences were considered significant at $P<0.05$.

\subsection{Results}

\subsubsection{Carotenoid profile in salad before and after simulated digestion}

Puréed salad contained LUT (+ZEA) (2.33mg / 100g), AC (1.17mg / 100g), alltrans BC (3.83mg / 100g), 9-cis BC (0.33mg / 100g) and LYC (3.72mg / 100g). All six carotenoids were detected and quantified in chyme and filtered aqueous (micelle) 
fraction after simulated digestion (Figure 3.1). Recovery of carotenoids ranged from $70 \%$ to $95 \%$, suggesting the relatively high stability during the gastric and small intestinal phases of digestion. The ratio of all - trans $\mathrm{BC}$ and 9 - cis $\mathrm{BC}$ did not change significantly $(P>0.05)$ in chyme compared to the undigested purée, suggesting limited isomerization. Because the concentration of 9-cis $\mathrm{BC}$ was quite low in filtered aqueous fraction, 9-cis $\mathrm{BC}$ will not be discussed further.

\subsubsection{Effect of TG with different fatty acyl groups on micellarization of carotenoids during simulated digestion of salad purée}

The amount of LUT (+ZEA), AC, BC, and LYC transferred to the filtered aqueous fraction during digestion of purée containing $2.5 \%(\mathrm{v} / \mathrm{w})$ canola oil was $35.7 \pm$ $0.6 \%, 13.1 \pm 0.2 \%, 14.3 \pm 0.1 \%$, and $4.8 \pm 0.1 \%$, respectively. In contrast, the relative amounts of $\mathrm{BC}, \mathrm{AC}$ and $\mathrm{LYC}$ in the aqueous fraction were only $3.2 \pm 0.2 \%, 1.9 \pm 0.3 \%$ and $1.0 \pm 0.1 \%$, respectively, when canola oil was not added to salad purée before digestion. Partitioning of LUT (+ZEA) into aqueous fraction during digestion of purée without canola oil was slightly, but significantly $(P<0.05)$, greater $(45.0 \pm 0.6 \%)$ than with canola oil. Several observations supported the conclusion that carotenoids in the filtered aqueous fraction were present in mixed micelles. First, deletion of pancreatin and pancreatic lipase during small intestinal phase of digestion of purée with $2.5 \%(\mathrm{v} /$ w) canola oil decreased efficiency of transfer of carotenoids into the filtered aqueous fraction to $16.1 \pm 0.4 \%$ for LUT (+ZEA) and less than detectable amounts for BC, AC and LYC. Second, only $2.0 \pm 0.1 \%$ of LUT (+ZEA) and no detectable BC, AC and LYC 


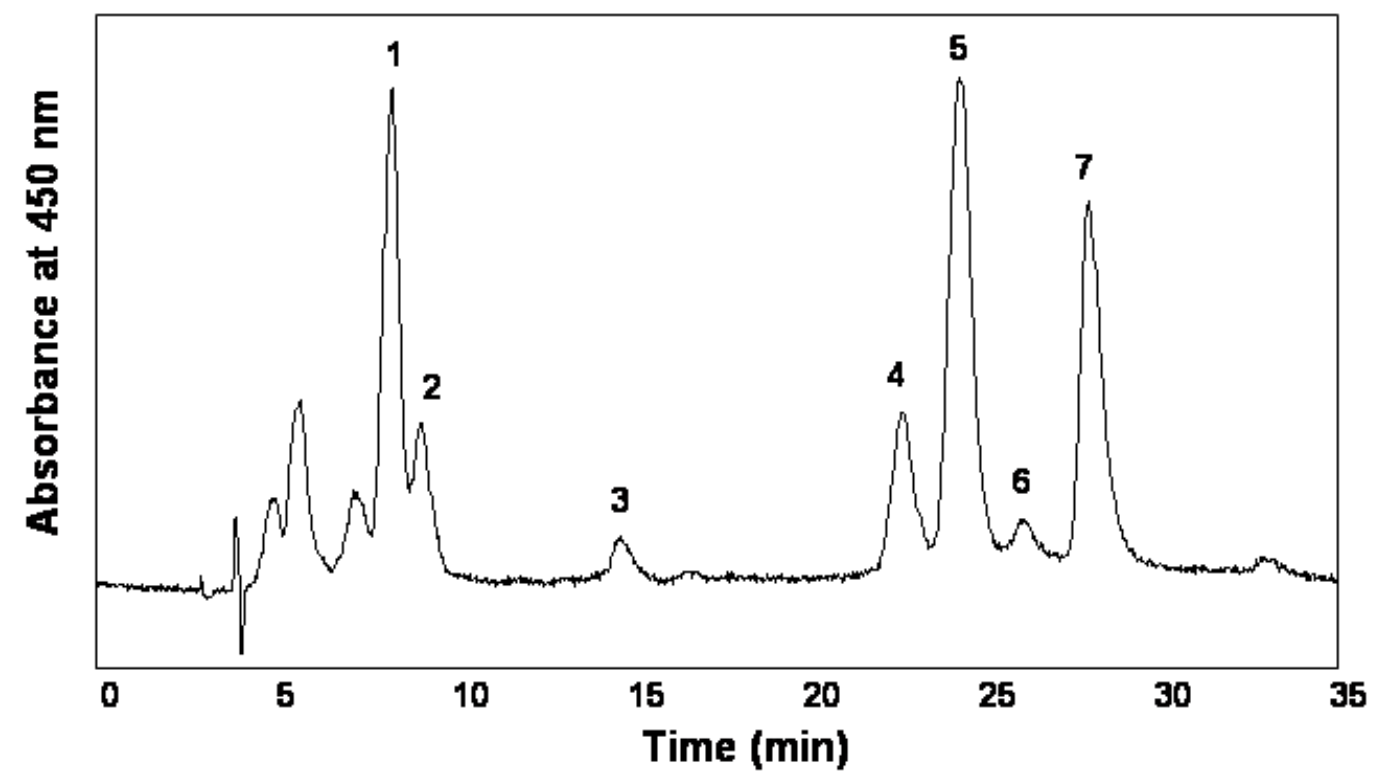

Figure 3.1: HPLC profile of representative chromatograms of carotenoids from the test salad purée. Carotenoid species were identified by comparison of retention times and absorption spectra with the pure carotenoid standards. 1. lutein; 2. zeaxanthin; 3. apo-8'$\beta$-carotenal (internal standard); 4. $\alpha$-carotene; 5. all-trans $\beta$-carotene; 6. 9-cis $\beta$-carotene; 7. lycopene. 
was present in aqueous fraction when bile extract was absent during small intestinal phase of digestion.

We investigated the effect of fatty acyl chain length and degree of unsaturation on micellarization of carotenoids in the salad purée by adding a single TG $(2.5 \%, \mathrm{v} / \mathrm{w})$ with the identical fatty acyl group in $s n-1, s n-2$ and $s n-3$ positions. Addition of tributyrin significantly $(P<0.05)$ increased micellarization of AC and BC, but not LYC, compared to that present in micelles after digestion of salad purée without TG (Table 3.1). Micellarization of AC and BC was further increased $(P<0.05)$ when either trioctanoin or triolein was added to the salad purée. Partitioning of LYC in micelles during digestion was significantly $(P<0.05)$ increased above control (i.e., no oil) by addition of trioctanoin to salad purée. Substitution of triolein for trioctanoin further enhanced $(P<$ 0.05) micellarization of LYC. Surprisingly, addition of all TG except trioctanoin slightly decreased micellarization of LUT (+ZEA). Because the molecular weights of TG with various acyl groups differ, we also compared efficiency of micellarization of the carotenoids when the amount of lipids added to the purée was expressed as $\mu$ mol per gram of salad purée. Micellarization of BC (Figure 3.2), like AC and LYC (data not shown), significantly increased with increasing acyl chain length of TG added to salad purée when expressed as either percentage (v/w) or $\mu$ mol per gram of salad purée.

Micellarization of carotenoids was not significantly altered by the degree of unsaturation of the c18 fatty acids (c18:1, c18:2 and c18:3) (Table 3.1). Similarly, the position of double bond of the fatty acid in TG did not affect the efficiency of micellarization of carotenoids during simulated digestion. Partitioning of carotenoids 


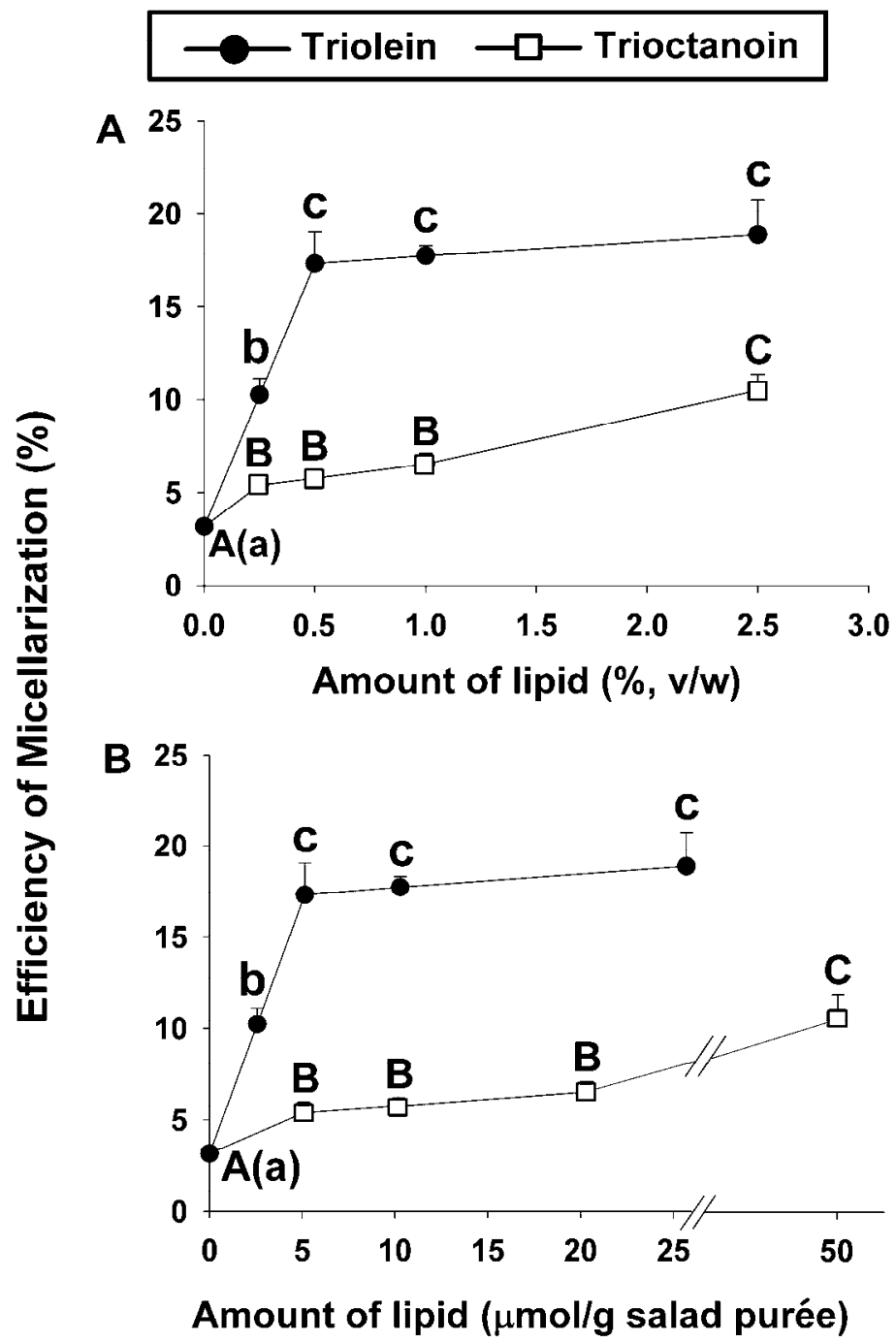

Figure 3.2: Addition of triolein to salad purée increases micellarization of $\beta$-carotene during simulated digestion more efficiently than trioctanoin. The amount of trioctanoin and triolein is expressed as \% volume (panel A) or $\mu \mathrm{mol}$ (panel B) added per gram of wet weight. Data are means \pm SEM from three independent digestions for each amount of TG added to salad purée. ( $n=3)$ Different letters above the error bars denote that the mean efficiency of micellarization of $\mathrm{BC}$ differ significantly $(P<0.05)$ in response to the amount of added TG with uppercase for trioctanoin and lower case for triolein. 
Efficiency of Micellarization (\%)

\begin{tabular}{lllll} 
& Lutein (+Zeaxanthin) & $\boldsymbol{\alpha}$-carotene & $\boldsymbol{\beta}$-carotene & Lycopene \\
\hline No Oil & $45.6 \pm 0.6^{\mathrm{c}}$ & $2.0 \pm 0.3^{\mathrm{a}}$ & $2.8 \pm 0.2^{\mathrm{a}}$ & $1.1 \pm 0.1^{\mathrm{a}}$ \\
c4:0 & $33.6 \pm 1.0^{\mathrm{a}}$ & $4.9 \pm 0.2^{\mathrm{b}}$ & $5.3 \pm 0.1^{\mathrm{b}}$ & $1.4 \pm 0.1^{\mathrm{a}}$ \\
c8:0 & $42.0 \pm 1.5^{\mathrm{b}, \mathrm{c}}$ & $8.6 \pm 0.7^{\mathrm{c}}$ & $10.5 \pm 0.9^{\mathrm{c}}$ & $2.9 \pm 0.2^{\mathrm{b}}$ \\
c18:1 & $34.8 \pm 1.5^{\mathrm{a}}$ & $14.9 \pm 1.1^{\mathrm{d}}$ & $17.7 \pm 1.3^{\mathrm{d}}$ & $5.2 \pm 0.5^{\mathrm{c}}$ \\
c18:2 & $34.9 \pm 0.4^{\mathrm{a}}$ & $15.3 \pm 0.7^{\mathrm{d}}$ & $18.5 \pm 0.3^{\mathrm{d}}$ & $5.6 \pm 0.6^{\mathrm{c}}$ \\
c18:3 & $38.2 \pm 1.5^{\mathrm{a}, \mathrm{b}}$ & $16.6 \pm 1.2^{\mathrm{d}}$ & $18.3 \pm 0.7^{\mathrm{d}}$ & $5.0 \pm 0.1^{\mathrm{c}}$ \\
\hline
\end{tabular}

* The salad purée ( $3 \mathrm{~g})$ was digested in vitro with $2.5 \%(\mathrm{v} / \mathrm{w})$ TG containing indicated fatty acyl groups in all three $s n$-positions of the glycerol backbone as described in Materials and Methods. Data (means \pm SEM) are the relative (\%) efficiency of micellarization of indicated carotenoids during in vitro digestion of salad purée containing test TG. Each TG was examined in two separate experiments with three independent digestions per experiment $(n=6)$. Presence of different letters as superscripts within a column indicates that efficiency of micellarization of the carotenoid significantly $(P<0.05)$ differed when purée was digested without and with indicated TG.

Table 3.1: Chain length, but not degree of unsaturation of acyl groups in TG affects micellarization of carotenoids during in vitro digestion of salad* 
into micelles during digestion of salad purée containing 2.5\% (v/w) TG as either 9-cis, 11-trans CLA, or 10 - trans, 12 - cis CLA was not significantly $(P>0.05)$ different from purée containing either triolein, trilinolein, or trilinolenin (data not shown).

Different amounts ( 0.0 to $2.5 \%, \mathrm{v} / \mathrm{w})$ of trioctanoin and triolein were added to purée that was digested to determine the quantity of TG required for maximum micellarization of carotenoids. Micellarization of $\mathrm{BC}$ and $\mathrm{AC}$ almost attained maximum $(17.3 \pm 3.4 \%$, Figure 3.2A $)$ and $(12.5 \pm 2.1 \%$, Figure 3.3A $)$ amounts when purée contained as low as $0.5 \%(\mathrm{v} / \mathrm{w})$ triolein. Micellarization of LYC was maximum $(8.0 \pm$ $0.8 \%$, Figure 3.3B) during digestion of purée with $1.0 \%(\mathrm{v} / \mathrm{w})$ triolein. In contrast, $2.5 \%$ $(\mathrm{v} / \mathrm{w})$ trioctanoin was required for maximum micellarization of $\mathrm{BC}(10.5 \pm 0.9 \%$, Figure 2A), AC $(8.6 \pm 0.7 \%$, Figure 3.3A $)$ and LYC $(2.9 \pm 0.2 \%$, Figure 3.3B $)$ during digestion. The extent of micellarization at all levels of trioctanoin was significantly $(P<$ 0.05) lower than samples containing an equivalent level of triolein in purée (Figures $\mathbf{3 . 2}$ and 3.3). Micellarization of LUT (+ZEA) during small intestinal digestion ranged from $38.4 \%$ to $45.0 \%$ at all concentrations of triolein and trioctanoin added to the salad purée (Figure 3.3C).

The effects of several commercial dietary oils on micellarization of carotenoids were comparable to that reported above for structured lipids with similar fatty acyl groups. Addition of as little as $0.25 \%(\mathrm{v} / \mathrm{w})$ canola oil to salad purée significantly $(P<$ 0.05) increased micellarization of carotenes (Figure 3.4). Greater amounts of canola oil further increased the efficiency of micellarization of $\mathrm{BC}$, AC and LYC to $25.4 \pm 1.8 \%$, 
Figure 3.3: Fatty acyl chain length and amount of TG affect micellarization of $\alpha$ carotene (AC), and lycopene (LYC), but not lutein + zeaxanthin (LUT+ZEA). Indicated amounts of either triolein or trioctanoin were added to the salad prior to simulated digestion. Micellarization of AC and LYC from the purée containing triolein was significantly higher than that from purée containing equivalent volume of trioctanoin. ( $P$ $<0.05$ ) Data was expressed as the means \pm SEM from three independent observations (n $=3$ ). Different letters above the error bars denote that the mean percentages of the indicated carotenoid micellarized differ significantly $(P<0.05)$ in response to the amounts of lipid added with uppercase for trioctanoin and lowercase for triolein. 

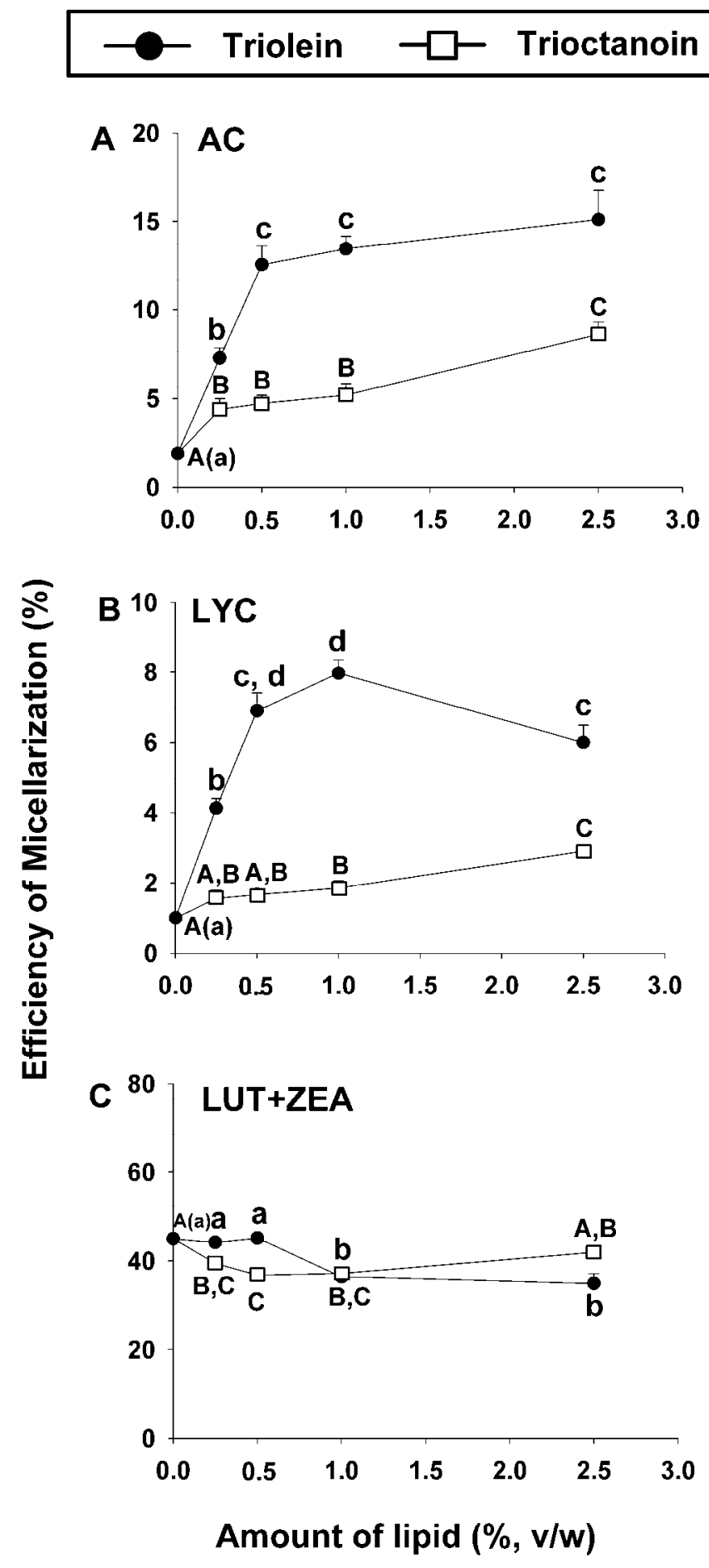


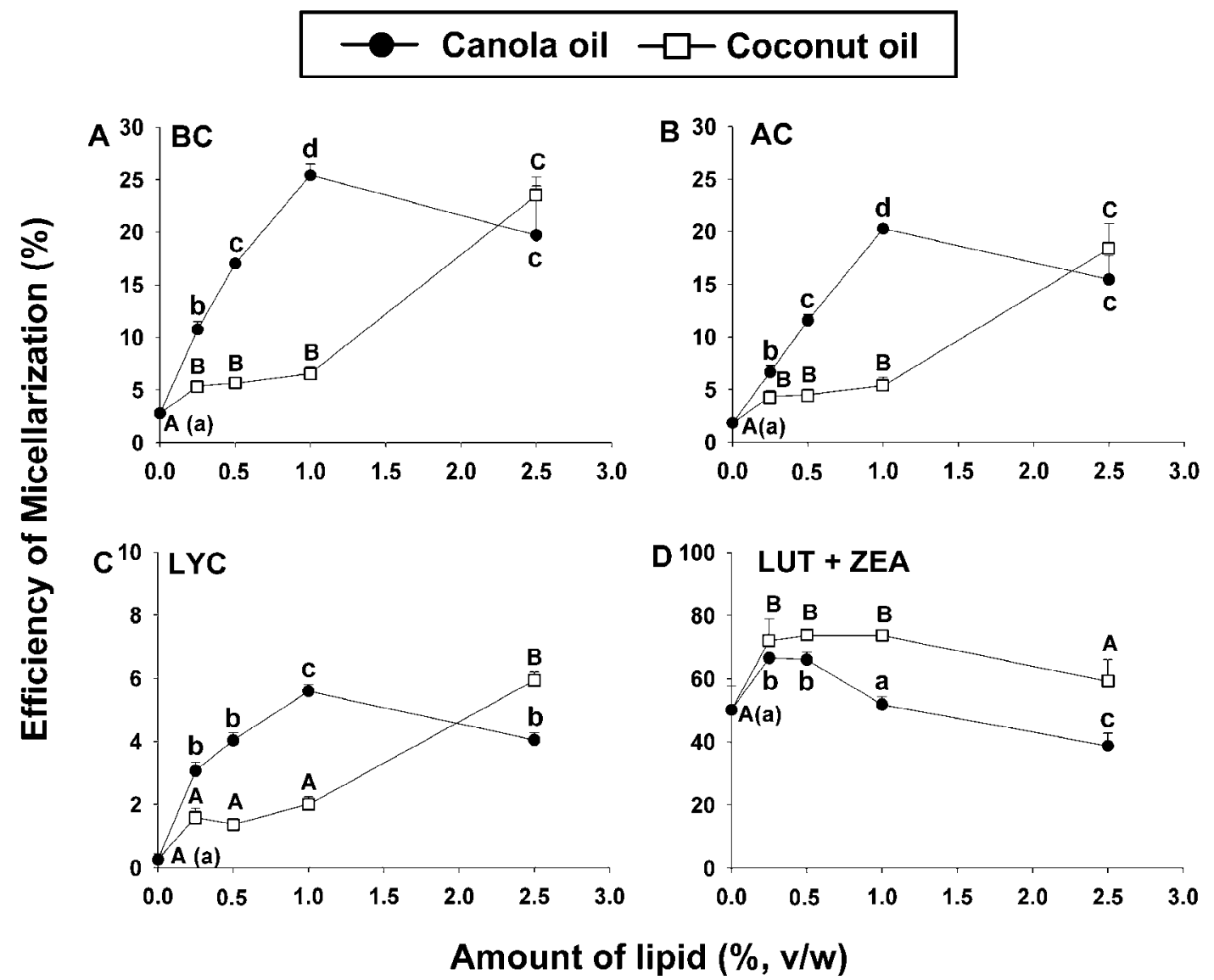

Figure 3.4: Maximum micellarization of carotenoids during simulated digestion of salad is dependent on type and amount of dietary oils. Salad purée was digested after addition of indicated concentration of either canola or coconut oil (v/w). Micellarization of BC, $\mathrm{AC}$ and LYC during digestion of salad containing 0.25 to $1 \%$ of canola oil were significantly greater than that from salad containing equivalent volume of coconut oil. Data are expressed as the means \pm SEM from three replicates. $(n=3)$ Different letters above or under the error bars denote that the mean percent of micellarization of the indicated carotenoid differ significantly in response to the concentration of lipid added with uppercase for coconut oil and lowercase for canola oil $(P<0.05)$. 
$20.3 \pm 0.8 \%$, and $5.6 \pm 0.4 \%$, respectively. Micellarization of the carotenes slightly decreased when the concentration of canola oil increased from 1.0 to $2.5 \%(\mathrm{v} / \mathrm{w})$. The presence of intact oil droplets on the surface of centrifuged digesta suggested incomplete hydrolysis of higher volume of TG. Micellarization of carotenes during digestion was not significantly different when $0.25-1.0 \%(\mathrm{v} / \mathrm{w})$ coconut oil was added to salad purée but increased markedly when salad purée contained $2.5 \%(\mathrm{v} / \mathrm{w})$ coconut oil. We also digested the salad purée with $2.5 \%(\mathrm{v} / \mathrm{w})$ safflower oil to determine if increasing the degree of fatty acyl unsaturation affected micellarization of carotenoids during digestion. Micellarization of LUT(+ZEA), BC, AC and LYC was $33.9 \pm 0.5 \%, 17.6 \pm 1.2 \%, 17.3 \pm$ $1.0 \%$ and $4.5 \pm 0.4 \%$, respectively, and not significantly $(P>0.05)$ different from micellarization of the four carotenoids when the same amount of canola oil was added to the salad purée.

\subsubsection{Effect of acyl chain length on uptake of micellar carotenoids by Caco-2 cells}

Cellular uptake of carotenoids was examined by incubating monolayers of Caco2 cells with serum free DMEM containing micelles generated during simulated digestion of spinach $(0.6 \mathrm{~g})$ and carrot $(1.0 \mathrm{~g})$ purée containing $2.5 \%(\mathrm{v} / \mathrm{w})$ triolein or trioctanoin. Concentrations of carotenoids in medium were varied by diluting the filtered aqueous fraction with "vacant" (i.e., carotenoid free) mixed micelles generated during simulated digestion of the test TG only. The highest concentrations of micellarized LUT, BC and AC in medium were $0.18 \mu \mathrm{M}, 0.10 \mu \mathrm{M}$ and $0.06 \mu \mathrm{M}$, respectively, which are within the range present in small intestine after a meal (121). The ratio of all-trans to 9-cis isomers of $\mathrm{BC}$ in the test media was not altered during the $4 \mathrm{~h}$ incubation of medium with 
micellar carotenoids in cell culture environment. Accumulation of both LUT and BC increased proportionally with increasing concentrations of the carotenoids in the test media regardless of fatty acyl chain length in the TG added to the purée (Figure 3.5). Cells accumulated $16.8 \%$ of LUT from medium $\left(y=0.168 x, R^{2}=0.93\right)$ during $4 \mathrm{~h}$ incubation with micelles generated from digested purée with triolein. Cells accumulated slightly, but significantly $(P<0.05)$, less LUT $(13.0 \%)$ from micelles produced during digestion of salad containing trioctanoin $\left(y=0.130 x, R^{2}=0.99\right)$. BC uptake was not significantly different $(P>0.05)$ from micelles produced during digestion of salad purée containing triolein $\left(13.5 \%, \mathrm{y}=0.135 \mathrm{x}, \mathrm{R}^{2}=0.81\right)$ and trioctanoin $(12.0 \%, \mathrm{y}=0.120 \mathrm{x}$, $\left.\mathrm{R}^{2}=0.91\right)$. Similarly, cells accumulated $13.5 \%\left(\mathrm{R}^{2}=0.87\right)$ and $10.7 \%\left(\mathrm{R}^{2}=0.81\right) \mathrm{AC}$ from micelles generated during digestion of purée with triolein and trioctanoin, respectively $(P>0.05)$.

\subsection{Discussion}

The 2005 Dietary Guidelines for Americans by the Departments of Health and Human Services (HHS) and Agriculture (USDA) recommend a reduction of fat intake and encourage replacement of saturated fatty acids with mono- and poly-unsaturated fatty acids to reduce the risk of cardiovascular diseases and obesity (18). However, the possible impact of such changes in dietary behavior on the bioavailability of ingested fat-soluble vitamins and other health-promoting lipophilic compounds has received limited attention. Because co-ingestion of dietary lipids potently promotes absorption of fat-soluble compounds in foods, optimizing the amount and type of dietary lipids in a meal for maximum bioavailability of fat soluble compounds without increasing calorie 
Figure 3.5: Fatty acyl chain length in dietary TG has minimum impact on efficiency of uptake of micellarized lutein (LUT) and $\beta$-carotene (BC) by Caco-2 cells. Preparation of micelles added to the cultures of Caco-2 cells is described in Materials and Methods. The highest concentrations of micellarized LUT and BC in media were $0.18 \mu \mathrm{M}$ and $0.10 \mu \mathrm{M}$, respectively (A) The efficiency of LUT uptake by Caco-2 cells from micelles generated during digestion of salad containing triolein (16.8\%) is slightly, but significantly $(P<0.05)$, greater than from micelles produced during digestion of salad containing trioctanoin (13.0\%). (B) Efficiency of uptake of BC by Caco-2 cells from micelles generated during digestion of salad with triolein (13.5\%) was not significantly different from that with trioctanoin (12.1\%). Uptake of LUT and BC uptake by Caco-2 cells was dose-dependent, regardless of TG added to salad. Data in panels A and B are from two experiments, and each point is the mean of two independent observations. Efficiency of carotenoid uptake for each carotenoid in each treatment is determined by the slope of the regression curves. 


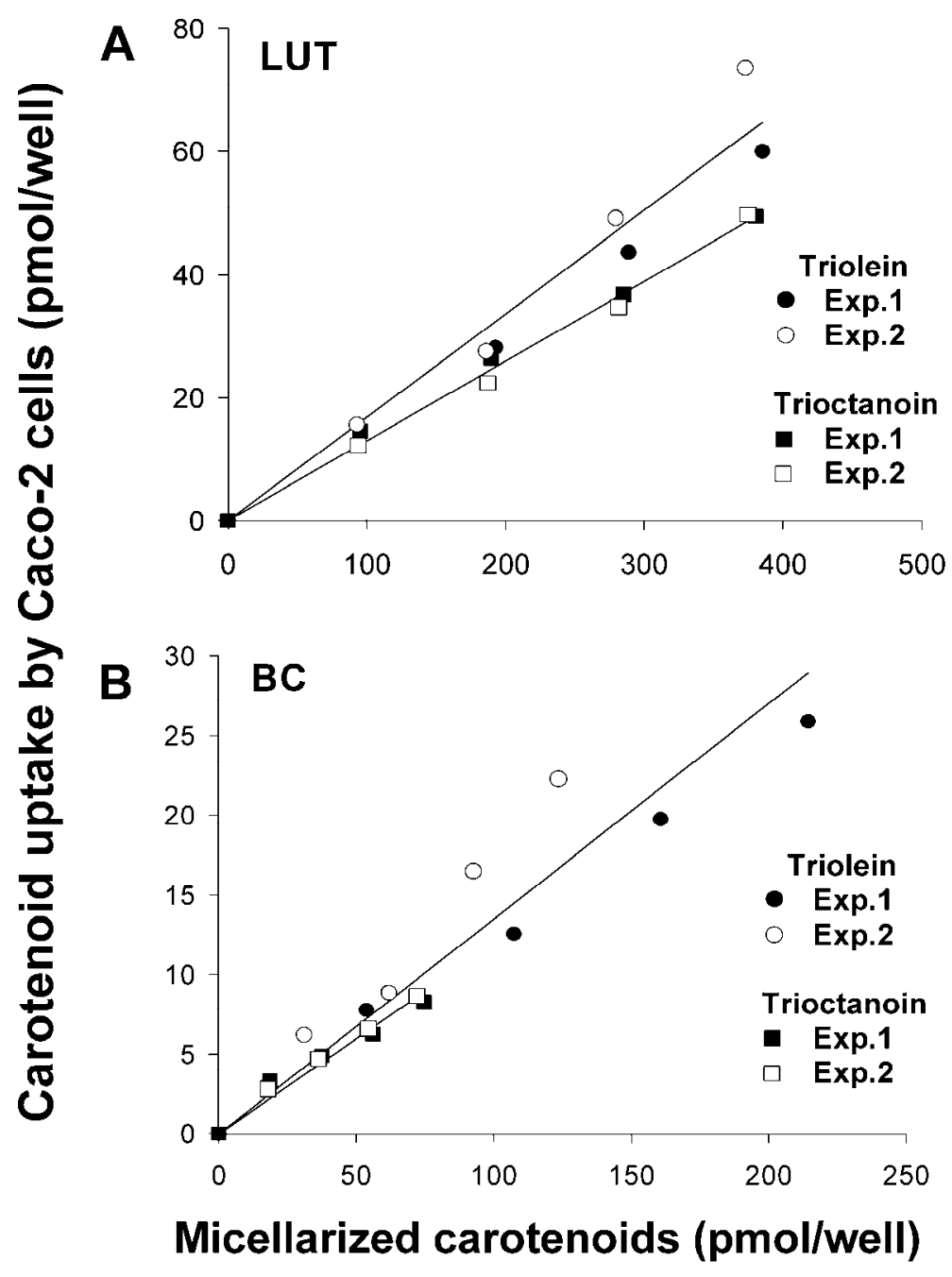


intake is important. The present study examined the effects of amount and type of dietary TG required for maximum micellarization of both hydrocarbon carotenoids and xanthophylls during the simulated digestion of a typical western salad. Micellarization represents a critical process for the delivery or accessibility of carotenoids for absorption. Experiments with structured TG including tributyrin, trioctanoin and triolein facilitated the evaluation of the impact of chain length and degree of unsaturation on carotenoid micellarization in a controlled fashion using a homogenous lipid system. The model system allows testing of specific hypotheses prior to more complex experiments with food grade oils and fats (e.g., safflower, canola and coconut oils).

As expected, the results demonstrate that partitioning of carotenoids into micelles during simulated digestion of salad was enhanced by addition of TG to the meal. Efficiency of micellarization of carotenoids from the salad was influenced by carotenoid structure. Moreover, we confirm that the efficiency of micellarization is inversely proportional to hydrophobicity with LUT (+ZEA) $>$ AC, BC $>$ LYC $(70,147)$. The results further show that micellarization of carotenes was dependent on TG acyl chain length, but not the number and position of double bonds. Relatively low amounts (approx. $0.5-1.0 \%, \mathrm{v} / \mathrm{w}$ ) of triolein and canola oil were required for maximum micellarization of carotenes, whereas greater quantities were required (approx. 2.5\%, v/w) if TG contained medium chain length saturated fatty acyl groups, e.g., trioctanoin and coconut oil. While the ability of octanoic acid to form micelle like structures has been demonstrated (153), the extent to which digestion products of tributyrin and trioctanoin partition in mixed lipid micelles in this model is unknown. Therefore, 
observed increases in apparent micellarization of carotenoids could be due to direct enhancement of micellarization or through another unknown mechanism facilitating the solubilization of carotenoids in the aqueous fraction.

Surprisingly, a decrease in micellarization of LUT (+ZEA) was observed with higher lipid levels (Table 3.1; Figures 3.3 and 3.4). While statistically significant, the slight decrease at higher lipid levels is likely an artifact of the static nature of the digestion model which did not completely hydrolyze at the highest amounts of lipids tested (2.5\%). The residual TG may have solubilized some of the released xanthophylls reducing the amount partitioned into micelles. While this appears to be an artifact of the model, the overall efficient micellarization of LUT (+ZEA) ( 40-50\%) without added lipid suggest that only minimal dietary lipid is required for effective solubilization of these polar carotenoids. However, lipid profile and quantity may play a more significant role in subsequent absorptive steps for xanthophylls. For example, the efficiency of LUT uptake by Caco-2 cells was slightly, although significantly, higher from micelles generated during digestion of salad with triolein compared to trioctanoin, while uptake of BC uptake was not affected by length or unsaturation of fatty acyl chains in added TG.

Numerous factors that influence carotenoid bioavailability have been reviewed elsewhere $(13,24)$. Dietary fat is required for the efficient absorption of carotenoids and may affect carotenoid bioaccessibility in several ways. First, dietary lipids provide a lipophilic "sink" to facilitate the transfer of carotenoids from food matrix to the oil droplets during the gastric phase of digestion. Second, dietary lipids stimulate secretion 
of pancreatic lipases and bile salts. The latter are emulsifiers that disrupt large oil droplets to form smaller droplets in which TG and other components are efficiently hydrolyzed by lipases (154). Third, the hydrolytic products of dietary lipids may modify physiochemical characteristics of micelles $(155,156)$, which possibly enhance the repartitioning of carotenoids into micelles. Because the standard in vitro digestion process is static with fixed amounts of bile salts and pancreatic enzymes, insights regarding the impact of various amounts and types of lipid on each of these steps are unknown. Nevertheless, the simulated digestion model has been used to estimate the bioaccessibility of LUT, ZEA, and all-trans and cis isomers of $\mathrm{BC}(53,70,71,131,147$, 157, 158). Borel and associates recently reported that micellarization during simulated digestion of vegetables and fruits provided a valid estimate of the bioaccessibility of carotenoids in vivo. Bioaccessibility as determined with the in vitro digestion model was well correlated with outcomes derived from human studies $(\mathrm{r}=0.90, P<0.05)(147)$.

In the present study, increased acyl chain length of TG was associated with greater efficiency of micellarization of BC, AC and LYC. This is consistent with previous studies showing that increased fatty acyl chain length (oleate $>$ octanoate $>$ butyrate) enhanced $\mathrm{BC}$ uptake in perfused rat small intestine (57), and that longer acyl chain length in phospholipids enhanced micellarization and uptake of BC by Caco-2 cells (159). Similarly, BC and retinyl palmitate in plasma chylomicrons were dramatically diminished when human subjects ingested BC along with TG containing medium rather than long chain fatty acyl moieties (112). Increased acyl chain length increases the hydrophobicity of products of lipid digestion possibly facilitating carotene 
transfer from the food matrix. Hydrolytic products with different chain length produced during gastric and small intestinal digestion also affect the physiochemical characteristics of mixed micelles and the longer chain acyl compounds likely enhance the re-partitioning of carotenes into micelles (156).

Previous investigators have reported that the degree of unsaturation of fatty acyl groups in dietary oils affect the absorption of carotenoids. Clark et al. observed that LYC and AST absorption in rats was greater when orally administered as an emulsion with olive oil compared to corn oil (108). Hu et al. showed greater absorption of BC and retinyl palmitate after subjects ingested a high fat meal containing beef tallow $(46.9 \%$ and $50.5 \%$ saturated and mono-unsaturated fatty acyl chains, respectively) instead of sunflower oil (68.9\% poly-unsaturated fatty acyl groups) (111). Our in vitro observations reveal that micellarization of carotenoids during simulated digestion of the salad was not altered by the degree of unsaturation of c18 fatty acids or the position of double bonds. This supports the likelihood that the degree of unsaturation of fatty acyl groups influences post-micellarization processes required for absorption such as delivery of the micellarized carotenoids to enterocytes (108) or incorporation and secretion of carotenoids in triacylglycerol-rich lipoproteins (111). Fatty acyl chain length and degree of unsaturation influence the physiochemical characteristics of micelles including size (160). We observed that $\mathrm{BC}$ uptake from mixed micelles generated during simulated digestion of salad containing trioctanoin was as efficient as from micelles generated during digestion of the salad containing triolein, suggesting acyl chain length has minimum impact on efficiency of cellular uptake of carotenes. LUT uptake was slightly 
$(<20 \%)$ higher from micelles generated from digested salad with triolein than from salad with trioctanoin. This suggests that differences in the properties of micelles resulting from the incorporation of digestion products of trioctanoin compared to triolein in micelles had minimal impact on the uptake of the carotenoids by Caco- 2 cells. Similarly, Yonekura et al. reported that BC uptake by Caco-2 cells was not proportional to the size of micelles containing either phosphatidylcholine (PC) or lyso-PC with varying fatty acyl chain length (159).

Human studies have reported the amount of dietary fat required for efficient absorption of carotenoids varies from 2.4 to $40 \mathrm{~g}$ per meal $(14,15,103,107,126)$. In the present study, we showed that addition of only $0.5-1.0 \%(\mathrm{v} / \mathrm{w})$ of triolein or canola oil increased micellarization of carotenes 5-10 fold, while 2.5\% trioctanoin or coconut oil was required to achieve maximum micellarization of carotenes (Figure 3.4). Based on the data from the Third National Health and Nutrition Examination Survey (NHANES III), the averages for consumption of salad and salad dressings are $\sim 40 \mathrm{~g} /$ day and 3-4 g/d, respectively (161). Regular, reduced-fat, low-fat and fat free salad dressings contain 10-20 g, 1-8 g, less than $3 \mathrm{~g}$ and less than $0.5 \mathrm{~g}$ of fat per serving, respectively. The amount of TG added in the salad purée in the present study is comparable to the fat content when reduced-fat or low-fat dressing is added to the salad. This suggests that the amount and type of dietary fat may affect both the extent of micellarization of carotenoids during digestion and the synthesis and secretion of chylomicrons containing carotenoids following their uptake from micelles. It is interesting that incubation of Caco-2 intestinal cells with oleate has been shown to stimulate chylomicron synthesis 
and secretion to a greater extent than linoleate, linolenate and palmitolyate $(113,162$, 163). Studies are now needed to clarify the effects of type and amounts of fatty acyl groups in foods on carotenoid secretion from human intestinal cells in order to better delineate the observed impact of dietary lipid on carotenoid absorption in vivo.

To summarize, addition of TG to a salad markedly increased the bioaccessibility of carotenes, but not xanthophylls, during in vitro digestion. The bioaccessibility of carotenes was enhanced by increased fatty acyl chain length, but not degree of unsaturation, of TG. Uptake of carotenoids from micelles was minimally affected by the fatty acyl composition of TG added to the salad. 


\section{CHAPTER 4}

\section{EPILOGUE}

Human studies have provided strong evidence that dietary lipids, particularly triglycerides, are a potent promoter of carotenoid bioavailability $(14,15,103)$. However, the adverse effects of consuming large amounts of TG, especially saturated fatty acids, necessitates a better understanding how the chemical structure of fatty acyl groups affect bioavailability, and the optimum amount of the TG required for maximum bioavailability of carotenoids.

There are several key steps affecting bioavailability of carotenoids. After ingestion of the meal containing carotenoids, these lipophilic compounds have to be released from the food matrix and solublized in oil droplets during oral and gastric digestion. The hydrophobicity of the lipid "pool" will affect the partitioning of carotenoids between the food matrix and the lipid "pool". Gastric lipase partially hydrolyzes the TG to diacylglycerides and free fatty acids, which also facilitate the emulsification of all the lipophilic compounds including carotenoids and also 
signal the secretion of bile and pancreatic enzymes to intestinal lumen for intestinal phase of digestion.

During small intestinal digestion, bile salts act as the natural emulsifiers to degrade the large oil droplets to small oil droplets and, simultaneously, the pancreatic lipase and colipase work on the surface of the oil droplets to hydrolyze the TG to monoacylglycerol and free fatty acids. Other lipophlic compounds, such as phospoholipids, cholesterol esters, xanthophyll esters, are hydrolyzed to lysophospholipids, free cholesterol, free xanthophylls respectively and also generate free fatty acids. All the hydrolytic products are amphipathic molecules, which contribute to the formation of mixed micelles, the small particles with the diameter of 10-100 nm $(164,165)$. Carotenoids have to be incorporated into mixed micelles to be accessible for uptake by small intestinal epithelium. The amount and type of digestive products of TG may affect the physiochemical characteristics of the mixed micelles, such as the size and the composition of the micelles. This may affect the efficiency of micellarization of carotenoids.

In the present study, TG with different fatty acyl chain length, but not the degree of unsaturation, showed different impact on micellarization of $\mathrm{AC}, \mathrm{BC}$ and $\mathrm{LYC}$ from the salad meal, suggesting the importance of the hydrophobicity of the TG co-ingested with the meal for bioaccessibility of carotenes. The greater the hydrophobicity of the TG in the meal, the hydrocarbon carotenoids are more likely transferred to the micelle fraction. Only minimum amount of TG $(0.5-1 \%$ of the meal $)$ is required for maximum micellarization of carotenoids, suggesting amount of TG is not a rate-limiting factor for 
carotenoid micellarization, particularly from a typical western style meal, which usually contains more than $30 \%$ of fat. However, in some areas of the developing countries, where no additional oil or very limited amount of oil is present in the daily meal, even the micellarization of carotenoids may be possibly a rate-limiting step. Other than facilitating micellarization, TG also promote secretion of pancreatic enzymes and bile salts, and these impacts on carotenoid micellarization have to be measured in the in vivo studies.

Once incorporated into the mixed micelles, carotenoids are accessible for small intestinal epithelial cells. The efficiency of carotenoids is also possibly affected by the characteristics of the mixed micelles. In the present study, carotenoid accumulation in the Caco-2 cells from micelles generated during digestion of the salad meal with different triglycerides did not significantly affect the efficiency of the uptake of BC. The cell accumulation of LUT was slightly, but significantly affected by the fatty acyl chain length of the TG added to the salad meal. Also, accumulation of both lutein and BC is proportional to the concentration of the compounds present in the mixed micelles. These results suggest that the characteristics of the mixed micelles have quite limited impact on carotenoid accumulation in the cells.

In the small intestinal cells, pro-vitamin A carotenoids are partially metabolized to retinal by BCO1. Retinal is further metabolized to RE. RE and other non pro-vitamin A carotenoids are incorporated into chylomicrons before secreted to the lymph. Both in vivo and in vitro studies have shown that oleic acid promotes chylomicron secretion compared to other fatty acids $(114,163,166)$. Secretion of RE, which is associated with 
chylomicrons, was also enhanced by treating Caco-2 cells with oleic acid compared to treating with palmitic acid (113). We expect that amount and type of fatty acids will impact carotenoid secretion via chylomicrons too. Also, more investigation is needed to determine the impact of different mixture of fatty acids and monoacylglycerols, on carotenoid secretion, as commercial dietary oils always contain mixture of fatty acyl groups.

The efficiency of the central cleavage of pro-vitamin A carotenoids by BCO1 within intestinal cells may also be regulated by the digestion products of TG with different fatty acyl groups (149). The amounts of the mixed fatty acid and monoacylglycerols needed for carotenoid metabolism and secretion from these cells is also unclear and needs further investigation. 


\section{ABBREVIATIONS}

ABCA1: ATP binding cassette transporter 1

$\mathrm{AC}: \alpha$-carotene

AST: astaxanthin

$\mathrm{BC}: \beta$-carotene

BCO1: $\beta$-carotene 15,15'-monooxygenase 1

BHT: butylated hydroxytoluene

CLA: conjugated linoleic acids

CRTISO: carotenoid isomerase

Cx43: connexin43

GGPP: geranylgeranyl pyrophosphate

GJC: gap junctional communication

$\mathrm{HCl}$ : hydrochloric acid

HDL: high density lipoproteins

IPP: isopentenyl diphosphate

LCY-B: lycopene $\beta$-cyclase

LCY-E: lycopene $\varepsilon$ - cyclase

LDL: low density lipoproteins

LRAT: lecithin: retinol acyltransferase

LUT: lutein

LXR: liver X receptor

MEP: methylerythritol 4-phosphate

NPC1L1: Niemann-Pick C1 Like 1

PDS: phytoene desaturase

PSY: phytoene synthease

RAR: retinoic acid receptor

RE: retinyl esters

ROS: reactive oxygen species

RXR: retinoid $X$ receptor

SR-B1: class B scavenger receptors type 1

TG: triglycerides

VLDL: very low density lipoproteins

ZDS: $\zeta$-carotene desaturase

ZEA: zeaxanthin 


\section{BIBLIOGRAPHY}

1. Stahl W, Sies H. Bioactivity and protective effects of natural carotenoids. Biochim Biophys Acta. 2005 May 30;1740(2):101-7.

2. Biesalski HK, Obermueller-Jevic UC. UV light, beta-carotene and human skin-beneficial and potentially harmful effects. Arch Biochem Biophys. 2001 May $1 ; 389(1): 1-6$.

3. Clinton SK. Tomatoes or lycopene: A role in prostate carcinogenesis? J Nutr. 2005 Aug;135(8):2057S-9S.

4. Snodderly DM. Evidence for protection against age-related macular degeneration by carotenoids and antioxidant vitamins. Am J Clin Nutr. 1995 Dec;62(6 Suppl):1448S$61 \mathrm{~S}$.

5. El-Agamey A, Lowe GM, McGarvey DJ, Mortensen A, Phillip DM, Truscott TG, Young AJ. Carotenoid radical chemistry and antioxidant/pro-oxidant properties. Arch Biochem Biophys. 2004 Oct 1;430(1):37-48.

6. Bertram JS. Induction of connexin 43 by carotenoids: Functional consequences. Arch Biochem Biophys. 2004 Oct 1;430(1):120-6.

7. Olson JA. Hypovitaminosis A: Contemporary scientific issues. J Nutr. 1994 Aug;124(8 Suppl):1461S-6S.

8. Brubacher GB, Weiser H. The vitamin A activity of beta-carotene. Int J Vitam Nutr Res. 1985;55(1):5-15.

9. Omenn GS, Goodman GE, Thornquist MD, Balmes J, Cullen MR, Glass A, Keogh JP, Meyskens FL,Jr, Valanis B, et al. Risk factors for lung cancer and for intervention effects in CARET, the beta-carotene and retinol efficacy trial. J Natl Cancer Inst. 1996 Nov 6;88(21):1550-9.

10. Omenn GS, Goodman G, Thornquist M, Barnhart S, Balmes J, Cherniack M, Cullen M, Glass A, Keogh J, et al. Chemoprevention of lung cancer: The beta-carotene and retinol efficacy trial (CARET) in high-risk smokers and asbestos-exposed workers. IARC Sci Publ. 1996;(136)(136):67-85. 
11. Olson JA. Bioavailability of carotenoids. Arch Latinoam Nutr. 1999 Sep;49(3 Suppl 1):21S-5S.

12. Faulks RM, Southon S. Challenges to understanding and measuring carotenoid bioavailability. Biochim Biophys Acta. 2005 May 30;1740(2):95-100.

13. Yonekura L, Nagao A. Intestinal absorption of dietary carotenoids. Mol Nutr Food Res. 2007 Jan;51(1):107-15.

14. Brown MJ, Ferruzzi MG, Nguyen ML, Cooper DA, Eldridge AL, Schwartz SJ, White WS. Carotenoid bioavailability is higher from salads ingested with full-fat than with fat-reduced salad dressings as measured with electrochemical detection. Am J Clin Nutr. 2004 Aug;80(2):396-403.

15. Unlu NZ, Bohn T, Clinton SK, Schwartz SJ. Carotenoid absorption from salad and salsa by humans is enhanced by the addition of avocado or avocado oil. J Nutr. 2005 Mar;135(3):431-6.

16. Kuller LH. Nutrition, lipids, and cardiovascular disease. Nutr Rev. 2006 Feb;64(2 Pt 2):S15-26.

17. Stoeckli R, Keller U. Nutritional fats and the risk of type 2 diabetes and cancer. Physiol Behav. 2004 Dec 30;83(4):611-5.

18. Department of Health and Human Services and U. S. Department of Agriculture. Dietary guidelines for Americans 2005. Jan, 2005.

19. Britton G, Liaaen-Jensen S, Pfander H. Carotenoids. Basel ; Boston: Birkhäuser Verlag; 1995.

20. Rodriguez-Amaya DB. Food carotenoids: Analysis, composition and alterations during storage and processing of foods. Forum Nutr. 2003;56:35-7.

21. Lichtenthaler HK. The 1-deoxy-D-xylulose-5-phosphate pathway of isoprenoid biosynthesis in plants. Annu Rev Plant Physiol Plant Mol Biol. 1999 Jun;50:47-65.

22. Stipanuk M. Biochemical, physiological \& molecular aspects of human nutrition. 2nd ed. Saunders; 2006.

23. Olson JA. Provitamin A function of carotenoids: The conversion of beta-carotene into vitamin A. J Nutr. 1989 Jan;119(1):105-8.

24. Yeum KJ, Russell RM. Carotenoid bioavailability and bioconversion. Annu Rev Nutr. 2002;22:483-504. 
25. Bastien J, Rochette-Egly C. Nuclear retinoid receptors and the transcription of retinoid-target genes. Gene. 2004 Mar 17;328:1-16.

26. Saari JC, Bredberg DL, Noy N. Control of substrate flow at a branch in the visual cycle. Biochemistry. 1994 Mar 15;33(10):3106-12.

27. Haliloglu S, Baspinar N, Serpek B, Erdem H, Bulut Z. Vitamin A and beta-carotene levels in plasma, corpus luteum and follicular fluid of cyclic and pregnant cattle. Reprod Domest Anim. 2002 Apr;37(2):96-9.

28. Bernstein PS, Zhao DY, Wintch SW, Ermakov IV, McClane RW, Gellermann W. Resonance raman measurement of macular carotenoids in normal subjects and in agerelated macular degeneration patients. Ophthalmology. 2002 Oct;109(10):1780-7.

29. Johnson EJ, Hammond BR, Yeum KJ, Qin J, Wang XD, Castaneda C, Snodderly DM, Russell RM. Relation among serum and tissue concentrations of lutein and zeaxanthin and macular pigment density. Am J Clin Nutr. 2000 Jun;71(6):1555-62.

30. Dwyer JH, Navab M, Dwyer KM, Hassan K, Sun P, Shircore A, Hama-Levy S, Hough $\mathrm{G}$, Wang $\mathrm{X}$, et al. Oxygenated carotenoid lutein and progression of early atherosclerosis: The los angeles atherosclerosis study. Circulation. 2001 Jun $19 ; 103(24): 2922-7$.

31. Iwamoto T, Hosoda K, Hirano R, Kurata H, Matsumoto A, Miki W, Kamiyama M, Itakura $\mathrm{H}$, Yamamoto S, Kondo K. Inhibition of low-density lipoprotein oxidation by astaxanthin. J Atheroscler Thromb. 2000;7(4):216-22.

32. Rissanen TH, Voutilainen S, Nyyssonen K, Lakka TA, Sivenius J, Salonen R, Kaplan GA, Salonen JT. Low serum lycopene concentration is associated with an excess incidence of acute coronary events and stroke: The kuopio ischaemic heart disease risk factor study. Br J Nutr. 2001 Jun;85(6):749-54.

33. Amir H, Karas M, Giat J, Danilenko M, Levy R, Yermiahu T, Levy J, Sharoni Y. Lycopene and 1,25-dihydroxyvitamin D3 cooperate in the inhibition of cell cycle progression and induction of differentiation in HL-60 leukemic cells. Nutr Cancer. 1999;33(1):105-12.

34. Karas M, Amir H, Fishman D, Danilenko M, Segal S, Nahum A, Koifmann A, Giat Y, Levy J, Sharoni Y. Lycopene interferes with cell cycle progression and insulin-like growth factor I signaling in mammary cancer cells. Nutr Cancer. 2000;36(1):101-11.

35. Nahum A, Hirsch K, Danilenko M, Watts CK, Prall OW, Levy J, Sharoni Y. Lycopene inhibition of cell cycle progression in breast and endometrial cancer cells is associated with reduction in cyclin D levels and retention of p27(Kip1) in the cyclin Ecdk2 complexes. Oncogene. 2001 Jun 7;20(26):3428-36. 
36. Murakoshi M, Takayasu J, Kimura O, Kohmura E, Nishino H, Iwashima A, Okuzumi J, Sakai T, Sugimoto T, Imanishi J. Inhibitory effects of alpha-carotene on proliferation of the human neuroblastoma cell line GOTO. J Natl Cancer Inst. 1989 Nov $1 ; 81(21): 1649-52$.

37. Pastori M, Pfander H, Boscoboinik D, Azzi A. Lycopene in association with alphatocopherol inhibits at physiological concentrations proliferation of prostate carcinoma cells. Biochem Biophys Res Commun. 1998 Sep 29;250(3):582-5.

38. Tang L, Jin T, Zeng X, Wang JS. Lycopene inhibits the growth of human androgenindependent prostate cancer cells in vitro and in BALB/c nude mice. J Nutr. 2005 Feb;135(2):287-90.

39. Tibaduiza EC, Fleet JC, Russell RM, Krinsky NI. Excentric cleavage products of beta-carotene inhibit estrogen receptor positive and negative breast tumor cell growth in vitro and inhibit activator protein-1-mediated transcriptional activation. J Nutr. 2002 Jun;132(6):1368-75.

40. Vine AL, Bertram JS. Upregulation of connexin 43 by retinoids but not by nonprovitamin A carotenoids requires RARs. Nutr Cancer. 2005;52(1):105-13.

41. Astorg P, Gradelet S, Leclerc J, Siess MH. Effects of provitamin A or nonprovitamin A carotenoids on liver xenobiotic-metabolizing enzymes in mice. Nutr Cancer. 1997;27(3):245-9.

42. Marill J, Idres N, Capron CC, Nguyen E, Chabot GG. Retinoic acid metabolism and mechanism of action: A review. Curr Drug Metab. 2003 Feb;4(1):1-10.

43. Halliwell B. Free radicals, proteins and DNA: Oxidative damage versus redox regulation. Biochem Soc Trans. 1996 Nov;24(4):1023-7.

44. Stahl W, Sies H. Antioxidant activity of carotenoids. Mol Aspects Med. 2003 Dec;24(6):345-51.

45. Polyakov NE, Leshina TV, Konovalova TA, Kispert LD. Carotenoids as scavengers of free radicals in a fenton reaction: Antioxidants or pro-oxidants? Free Radic Biol Med. 2001 Aug 1;31(3):398-404.

46. Frank HA, Cogdell RJ. Carotenoids in photosynthesis. Photochem Photobiol. 1996 Mar;63(3):257-64.

47. von Baeyer H, Hopfenmuller W, Riedel E, Affeld K. Atherosclerosis: Current concepts of pathophysiology and pharmacological intervention based on trial outcomes. Clin Nephrol. 2003 Jul;60 Suppl 1:S31-48. 
48. Sharoni Y, Danilenko M, Dubi N, Ben-Dor A, Levy J. Carotenoids and transcription. Arch Biochem Biophys. 2004 Oct 1;430(1):89-96.

49. Palozza P, Serini S, Di Nicuolo F, Calviello G. Modulation of apoptotic signalling by carotenoids in cancer cells. Arch Biochem Biophys. 2004 Oct 1;430(1):104-9.

50. Bertram JS. Carotenoids and gene regulation. Nutr Rev. 1999 Jun;57(6):182-91.

51. Borel P. Factors affecting intestinal absorption of highly lipophilic food microconstituents (fat-soluble vitamins, carotenoids and phytosterols). Clin Chem Lab Med. 2003 Aug;41(8):979-94.

52. Harrison EH. Mechanisms of digestion and absorption of dietary vitamin A. Annu Rev Nutr. 2005;25:87-103.

53. Thakkar SK, Maziya-Dixon B, Dixon AG, Failla ML. \{Beta\}-carotene micellarization during in vitro digestion and uptake by caco-2 cells is directly proportional to \{beta\}-carotene content in different genotypes of cassava. J Nutr. 2007 Oct;137(10):2229-33.

54. Borel P, Grolier P, Armand M, Partier A, Lafont H, Lairon D, Azais-Braesco V. Carotenoids in biological emulsions: Solubility, surface-to-core distribution, and release from lipid droplets. J Lipid Res. 1996 Feb;37(2):250-61.

55. El-Gorab MI, Underwood BA, Loerch JD. The roles of bile salts in the uptake of beta-carotene and retinol by rat everted gut sacs. Biochim Biophys Acta. 1975 Aug 20;401(2):265-77.

56. Micozzi MS, Brown ED, Edwards BK, Bieri JG, Taylor PR, Khachik F, Beecher GR, Smith JC,Jr. Plasma carotenoid response to chronic intake of selected foods and beta-carotene supplements in men. Am J Clin Nutr. 1992 Jun;55(6):1120-5.

57. Hollander D, Ruble PE,Jr. Beta-carotene intestinal absorption: Bile, fatty acid, pH, and flow rate effects on transport. Am J Physiol. 1978 Dec;235(6):E686-91.

58. Parker RS. Absorption, metabolism, and transport of carotenoids. FASEB J. 1996 Apr;10(5):542-51.

59. Diwadkar-Navsariwala V, Novotny JA, Gustin DM, Sosman JA, Rodvold KA, Crowell JA, Stacewicz-Sapuntzakis M, Bowen PE. A physiological pharmacokinetic model describing the disposition of lycopene in healthy men. J Lipid Res. 2003 Oct;44(10):1927-39.

60. van Bennekum A, Werder M, Thuahnai ST, Han CH, Duong P, Williams DL, Wettstein P, Schulthess G, Phillips MC, Hauser H. Class B scavenger receptor-mediated 
intestinal absorption of dietary beta-carotene and cholesterol. Biochemistry. 2005 Mar 22;44(11):4517-25.

61. Reboul E, Abou L, Mikail C, Ghiringhelli O, Andre M, Portugal H, JourdheuilRahmani D, Amiot MJ, Lairon D, Borel P. Lutein transport by caco-2 TC-7 cells occurs partly by a facilitated process involving the scavenger receptor class B type I (SR-BI). Biochem J. 2005 Apr 15;387(Pt 2):455-61.

62. During A, Dawson HD, Harrison EH. Carotenoid transport is decreased and expression of the lipid transporters SR-BI, NPC1L1, and ABCA1 is downregulated in caco-2 cells treated with ezetimibe. J Nutr. 2005 Oct;135(10):2305-12.

63. Connor WE, Duell PB, Kean R, Wang Y. The prime role of HDL to transport lutein into the retina: Evidence from HDL-deficient WHAM chicks having a mutant ABCA1 transporter. Invest Ophthalmol Vis Sci. 2007 Sep;48(9):4226-31.

64. Ferreira AL, Yeum KJ, Liu C, Smith D, Krinsky NI, Wang XD, Russell RM. Tissue distribution of lycopene in ferrets and rats after lycopene supplementation. J Nutr. 2000 May;130(5):1256-60.

65. Krinsky NI, Landrum JT, Bone RA. Biologic mechanisms of the protective role of lutein and zeaxanthin in the eye. Annu Rev Nutr. 2003;23:171-201.

66. Zaripheh S, Erdman JW,Jr. Factors that influence the bioavailablity of xanthophylls. J Nutr. 2002 Mar;132(3):531S-4S.

67. West CE, Castenmiller JJ. Quantification of the "SLAMENGHI" factors for carotenoid bioavailability and bioconversion. Int J Vitam Nutr Res. 1998;68(6):371-7.

68. Rich GT, Bailey AL, Faulks RM, Parker ML, Wickham MS, Fillery-Travis A. Solubilization of carotenoids from carrot juice and spinach in lipid phases: I. modeling the gastric lumen. Lipids. 2003 Sep;38(9):933-45.

69. van het Hof KH, Brouwer IA, West CE, Haddeman E, Steegers-Theunissen RP, van Dusseldorp M, Weststrate JA, Eskes TK, Hautvast JG. Bioavailability of lutein from vegetables is 5 times higher than that of beta-carotene. Am J Clin Nutr. 1999 Aug;70(2):261-8.

70. Garrett DA, Failla ML, Sarama RJ. Development of an in vitro digestion method to assess carotenoid bioavailability from meals. J Agric Food Chem. 1999

Oct;47(10):4301-9.

71. Chitchumroonchokchai C, Failla ML. Hydrolysis of zeaxanthin esters by carboxyl ester lipase during digestion facilitates micellarization and uptake of the xanthophyll by caco-2 human intestinal cells. J Nutr. 2006 Mar;136(3):588-94. 
72. Rich GT, Faulks RM, Wickham MS, Fillery-Travis A. Solubilization of carotenoids from carrot juice and spinach in lipid phases: II. modeling the duodenal environment. Lipids. 2003 Sep;38(9):947-56.

73. Stahl W, Schwarz W, Sundquist AR, Sies H. Cis-trans isomers of lycopene and betacarotene in human serum and tissues. Arch Biochem Biophys. 1992 Apr;294(1):173-7.

74. Boileau AC, Merchen NR, Wasson K, Atkinson CA, Erdman JW,Jr. Cis-lycopene is more bioavailable than trans-lycopene in vitro and in vivo in lymph-cannulated ferrets. $\mathrm{J}$ Nutr. 1999 Jun;129(6):1176-81.

75. Moraru C, Lee TC. Kinetic studies of lycopene isomerization in a tributyrin model system at gastric pH. J Agric Food Chem. 2005 Nov 16;53(23):8997-9004.

76. Holloway DE, Yang M, Paganga G, Rice-Evans CA, Bramley PM. Isomerization of dietary lycopene during assimilation and transport in plasma. Free Radic Res. 2000 Jan;32(1):93-102.

77. Tamai H, Morinobu T, Murata T, Manago M, Mino M. 9-cis beta-carotene in human plasma and blood cells after ingestion of beta-carotene. Lipids. 1995 Jun;30(6):493-8.

78. Stahl W, Sies H. Uptake of lycopene and its geometrical isomers is greater from heat-processed than from unprocessed tomato juice in humans. J Nutr. 1992 Nov;122(11):2161-6.

79. Stahl W, Schwarz W, Sies H. Human serum concentrations of all-trans beta- and alpha-carotene but not 9-cis beta-carotene increase upon ingestion of a natural isomer mixture obtained from dunaliella salina (betatene). J Nutr. 1993 May;123(5):847-51.

80. Levin G, Mokady S. Incorporation of all-trans- or 9-cis-beta-carotene into mixed micelles in vitro. Lipids. 1995 Feb;30(2):177-9.

81. You CS, Parker RS, Goodman KJ, Swanson JE, Corso TN. Evidence of cis-trans isomerization of 9-cis-beta-carotene during absorption in humans. Am J Clin Nutr. 1996 Aug;64(2):177-83.

82. During A, Hussain MM, Morel DW, Harrison EH. Carotenoid uptake and secretion by CaCo-2 cells: Beta-carotene isomer selectivity and carotenoid interactions. J Lipid Res. 2002 Jul;43(7):1086-95.

83. Castenmiller JJ, West CE, Linssen JP, van het Hof KH, Voragen AG. The food matrix of spinach is a limiting factor in determining the bioavailability of beta-carotene and to a lesser extent of lutein in humans. J Nutr. 1999 Feb;129(2):349-55. 
84. Kostic D, White WS, Olson JA. Intestinal absorption, serum clearance, and interactions between lutein and beta-carotene when administered to human adults in separate or combined oral doses. Am J Clin Nutr. 1995 Sep;62(3):604-10.

85. Livny O, Reifen R, Levy I, Madar Z, Faulks R, Southon S, Schwartz B. Betacarotene bioavailability from differently processed carrot meals in human ileostomy volunteers. Eur J Nutr. 2003 Dec;42(6):338-45.

86. van het Hof KH, de Boer BC, Tijburg LB, Lucius BR, Zijp I, West CE, Hautvast JG, Weststrate JA. Carotenoid bioavailability in humans from tomatoes processed in different ways determined from the carotenoid response in the triglyceride-rich lipoprotein fraction of plasma after a single consumption and in plasma after four days of consumption. J Nutr. 2000 May;130(5):1189-96.

87. Edwards AJ, Nguyen CH, You CS, Swanson JE, Emenhiser C, Parker RS. Alphaand beta-carotene from a commercial puree are more bioavailable to humans than from boiled-mashed carrots, as determined using an extrinsic stable isotope reference method. J Nutr. 2002 Feb;132(2):159-67.

88. Sundaresan PR, Marmillot P, Liu QH, Mitchell GV, Grundel E, Lakshman MR. Effects of dietary taurocholate, fat and protein on the storage and metabolism of dietary beta-carotene and alpha-tocopherol in ferrets. Int J Vitam Nutr Res. 2005 Mar;75(2):133-41.

89. Riedl J, Linseisen J, Hoffmann J, Wolfram G. Some dietary fibers reduce the absorption of carotenoids in women. J Nutr. 1999 Dec;129(12):2170-6.

90. Rock CL, Lovalvo JL, Emenhiser C, Ruffin MT, Flatt SW, Schwartz SJ.

Bioavailability of beta-carotene is lower in raw than in processed carrots and spinach in women. J Nutr. 1998 May;128(5):913-6.

91. Zanutto ME, Jordao Junior AA, Meirelles MS, Favaro RM, Vannucchi H. Effect of citric pectin on beta-carotene bioavailability in rats. Int J Vitam Nutr Res. 2002 Jul;72(4):199-203.

92. Judd JT, Baer DJ, Chen SC, Clevidence BA, Muesing RA, Kramer M, Meijer GW. Plant sterol esters lower plasma lipids and most carotenoids in mildly hypercholesterolemic adults. Lipids. 2002 Jan;37(1):33-42.

93. Weststrate JA, van het Hof KH. Sucrose polyester and plasma carotenoid concentrations in healthy subjects. Am J Clin Nutr. 1995 Sep;62(3):591-7.

94. Baskaran V, Sugawara T, Nagao A. Phospholipids affect the intestinal absorption of carotenoids in mice. Lipids. $2003 \mathrm{Jul}$;38(7):705-11. 
95. Sugawara T, Kushiro M, Zhang H, Nara E, Ono H, Nagao A.

Lysophosphatidylcholine enhances carotenoid uptake from mixed micelles by caco-2 human intestinal cells. J Nutr. 2001 Nov;131(11):2921-7.

96. van den Berg H, van Vliet T. Effect of simultaneous, single oral doses of betacarotene with lutein or lycopene on the beta-carotene and retinyl ester responses in the triacylglycerol-rich lipoprotein fraction of men. Am J Clin Nutr. 1998 Jul;68(1):82-9.

97. van den Berg H. Carotenoid interactions. Nutr Rev. 1999 Jan;57(1):1-10.

98. Lemke SL, Dueker SR, Follett JR, Lin Y, Carkeet C, Buchholz BA, Vogel JS, Clifford AJ. Absorption and retinol equivalence of beta-carotene in humans is influenced by dietary vitamin A intake. J Lipid Res. 2003 Aug;44(8):1591-600.

99. Tang G, Serfaty-Lacrosniere C, Camilo ME, Russell RM. Gastric acidity influences the blood response to a beta-carotene dose in humans. Am J Clin Nutr. 1996 Oct;64(4):622-6.

100. Takyi EE. Children's consumption of dark green, leafy vegetables with added fat enhances serum retinol. J Nutr. 1999 Aug;129(8):1549-54.

101. Parvin SG, Sivakumar B. Nutritional status affects intestinal carotene cleavage activity and carotene conversion to vitamin A in rats. J Nutr. 2000 Mar;130(3):573-7.

102. During A, Fields M, Lewis CG, Smith JC. Intestinal beta-carotene 15,15'dioxygenase activity is markedly enhanced in copper-deficient rats fed on high-iron diets and fructose. Br J Nutr. 2000 Jul;84(1):117-24.

103. Jayarajan P, Reddy V, Mohanram M. Effect of dietary fat on absorption of beta carotene from green leafy vegetables in children. Indian J Med Res. 1980 Jan;71:53-6.

104. Clark RM, Furr HC. Absorption of canthaxanthin by the rat is influenced by total lipid in the intestinal lumen. Lipids. 2001 May;36(5):473-5.

105. Borel P, Dubois C, Mekki N, Grolier P, Partier A, Alexandre-Gouabau MC, Lairon D, Azais-Braesco V. Dietary triglycerides, up to $40 \mathrm{~g} / \mathrm{meal}$, do not affect preformed vitamin A bioavailability in humans. Eur J Clin Nutr. 1997 Nov;51(11):717-22.

106. Fielding JM, Rowley KG, Cooper P, O'Dea K. Increases in plasma lycopene concentration after consumption of tomatoes cooked with olive oil. Asia Pac J Clin Nutr. 2005;14(2):131-6.

107. Roodenburg AJ, Leenen R, van het Hof KH, Weststrate JA, Tijburg LB. Amount of fat in the diet affects bioavailability of lutein esters but not of alpha-carotene, betacarotene, and vitamin E in humans. Am J Clin Nutr. 2000 May;71(5):1187-93. 
108. Clark RM, Yao L, She L, Furr HC. A comparison of lycopene and astaxanthin absorption from corn oil and olive oil emulsions. Lipids. 2000 Jul;35(7):803-6.

109. Lakshminarayana R, Raju M, Krishnakantha TP, Baskaran V. Lutein and zeaxanthin in leafy greens and their bioavailability: Olive oil influences the absorption of dietary lutein and its accumulation in adult rats. J Agric Food Chem. 2007 Jul 25;55(15):6395-400.

110. Fielding JM, Li D, Stockmann R, Sinclair AJ. The effect of different plant oils used in preparing tomato sauces on plasma concentrations of lycopene and oxidative status: A dietary intervention study. Asia Pac J Clin Nutr. 2004;13(Suppl):S49.

111. Hu X, Jandacek RJ, White WS. Intestinal absorption of beta-carotene ingested with a meal rich in sunflower oil or beef tallow: Postprandial appearance in triacylglycerolrich lipoproteins in women. Am J Clin Nutr. 2000 May;71(5):1170-80.

112. Borel P, Tyssandier V, Mekki N, Grolier P, Rochette Y, Alexandre-Gouabau MC, Lairon D, Azais-Braesco V. Chylomicron beta-carotene and retinyl palmitate responses are dramatically diminished when men ingest beta-carotene with medium-chain rather than long-chain triglycerides. J Nutr. 1998 Aug;128(8):1361-7.

113. Nayak N, Harrison EH, Hussain MM. Retinyl ester secretion by intestinal cells: A specific and regulated process dependent on assembly and secretion of chylomicrons. $\mathrm{J}$ Lipid Res. 2001 Feb;42(2):272-80.

114. van Greevenbroek MM, Voorhout WF, Erkelens DW, van Meer G, de Bruin TW. Palmitic acid and linoleic acid metabolism in caco-2 cells: Different triglyceride synthesis and lipoprotein secretion. J Lipid Res. 1995 Jan;36(1):13-24.

115. Bateman PA, Jackson KG, Maitin V, Yaqoob P, Williams CM. Differences in cell morphology, lipid and apo B secretory capacity in caco-2 cells following long term treatment with saturated and monounsaturated fatty acids. Biochim Biophys Acta. 2007 Apr;1771(4):475-85.

116. Congdon NG, West KP,Jr. Physiologic indicators of vitamin A status. J Nutr. 2002 Sep;132(9 Suppl):2889S-94S.

117. Christian P, West KP,Jr, Khatry SK, Katz J, LeClerq SC, Kimbrough-Pradhan E, Dali SM, Shrestha SR. Vitamin A or beta-carotene supplementation reduces symptoms of illness in pregnant and lactating nepali women. J Nutr. 2000 Nov;130(11):2675-82.

118. Van Lieshout M, West CE, Van De Bovenkamp P, Wang Y, Sun Y, Van Breemen RB, Muhilal DP, Verhoeven MA, Creemers AF, Lugtenburg J. Extraction of carotenoids from feces, enabling the bioavailability of beta-carotene to be studied in indonesian children. J Agric Food Chem. 2003 Aug 13;51(17):5123-30. 
119. Bowen PE, Mobarhan S, Smith JC,Jr. Carotenoid absorption in humans. Methods Enzymol. 1993;214:3-17.

120. Faulks RM, Hart DJ, Brett GM, Dainty JR, Southon S. Kinetics of gastro-intestinal transit and carotenoid absorption and disposal in ileostomy volunteers fed spinach meals. Eur J Nutr. 2004 Feb;43(1):15-22.

121. Tyssandier V, Reboul E, Dumas JF, Bouteloup-Demange C, Armand M, Marcand J, Sallas M, Borel P. Processing of vegetable-borne carotenoids in the human stomach and duodenum. Am J Physiol Gastrointest Liver Physiol. 2003 Jun;284(6):G913-23.

122. Cardinault N, Tyssandier V, Grolier P, Winklhofer-Roob BM, Ribalta J, Bouteloup-Demange C, Rock E, Borel P. Comparison of the postprandial chylomicron carotenoid responses in young and older subjects. Eur J Nutr. 2003 Dec;42(6):315-23.

123. Furr HC, Green MH, Haskell M, Mokhtar N, Nestel P, Newton S, Ribaya-Mercado JD, Tang G, Tanumihardjo S, Wasantwisut E. Stable isotope dilution techniques for assessing vitamin A status and bioefficacy of provitamin A carotenoids in humans. Public Health Nutr. 2005 Sep;8(6):596-607.

124. Tang G, Qin J, Dolnikowski GG, Russell RM. Vitamin A equivalence of betacarotene in a woman as determined by a stable isotope reference method. Eur J Nutr. $2000 \mathrm{Feb} ; 39(1): 7-11$.

125. Wang Z, Yin S, Zhao X, Russell RM, Tang G. Beta-carotene-vitamin A equivalence in chinese adults assessed by an isotope dilution technique. Br J Nutr. 2004 Jan;91(1):121-31.

126. Ribaya-Mercado JD, Maramag CC, Tengco LW, Dolnikowski GG, Blumberg JB, Solon FS. Carotene-rich plant foods ingested with minimal dietary fat enhance the totalbody vitamin A pool size in filipino schoolchildren as assessed by stable-isotopedilution methodology. Am J Clin Nutr. 2007 Apr;85(4):1041-9.

127. Lee CM, Boileau AC, Boileau TW, Williams AW, Swanson KS, Heintz KA, Erdman JW,Jr. Review of animal models in carotenoid research. J Nutr. 1999 Dec;129(12):2271-7.

128. Lee CM, Lederman JD, Hofmann NE, Erdman JW. The mongolian gerbil (meriones unguiculatus) is an appropriate animal model for evaluation of the conversion of beta-carotene to vitamin A. J Nutr. 1998 Feb;128(2):280-6.

129. Howe JA, Tanumihardjo SA. Carotenoid-biofortified maize maintains adequate vitamin a status in mongolian gerbils. J Nutr. 2006 Oct;136(10):2562-7.

130. Dosti MP, Mills JP, Simon PW, Tanumihardjo SA. Bioavailability of beta-carotene (betaC) from purple carrots is the same as typical orange carrots while high-betaC 
carrots increase betaC stores in mongolian gerbils (meriones unguiculatus). Br J Nutr. 2006 Aug;96(2):258-67.

131. Chitchumroonchokchai C, Schwartz SJ, Failla ML. Assessment of lutein bioavailability from meals and a supplement using simulated digestion and caco-2 human intestinal cells. J Nutr. 2004 Sep;134(9):2280-6.

132. Gireesh T, Nair PP, Sudhakaran PR. Studies on the bioavailability of the provitamin A carotenoid, beta-carotene, using human exfoliated colonic epithelial cells. Br J Nutr. 2004 Aug;92(2):241-5.

133. Failla ML, Chitchumroonchokchai C. In vitro models as tools for screening the relative bioavailabilities of provitamin A carotenoids in foods. Harvestplus; 2005. Available from: http://www.harvestplus.org/pdfs/tech03.pdf.

134. Failla ML, Huo T, Thakkar SK. In vitro screening of relative bioaccessibility of carotenoids from foods. Asian Pacific J Clin Nutr. 2008.

135. Gong X, Tsai SW, Yan B, Rubin LP. Cooperation between MEF2 and PPARgamma in human intestinal beta,beta-carotene 15,15'-monooxygenase gene expression. BMC Mol Biol. 2006 Feb 21;7:7.

136. Hussain MM. A proposed model for the assembly of chylomicrons. Atherosclerosis. $2000 \mathrm{Jan} ; 148(1): 1-15$.

137. Pauquai T, Bouchoux J, Chateau D, Vidal R, Rousset M, Chambaz J, Demignot S. Adaptation of enterocytic caco-2 cells to glucose modulates triacylglycerol-rich lipoprotein secretion through triacylglycerol targeting into the endoplasmic reticulum lumen. Biochem J. 2006 Apr 15;395(2):393-403.

138. Sambuy Y, De Angelis I, Ranaldi G, Scarino ML, Stammati A, Zucco F. The caco2 cell line as a model of the intestinal barrier: Influence of cell and culture-related factors on caco-2 cell functional characteristics. Cell Biol Toxicol. 2005 Jan;21(1):1-26.

139. Trotter PJ, Ho SY, Storch J. Fatty acid uptake by caco-2 human intestinal cells. J Lipid Res. 1996 Feb;37(2):336-46.

140. Adibi SA. The oligopeptide transporter (pept-1) in human intestine: Biology and function. Gastroenterology. 1997 Jul;113(1):332-40.

141. Anwar K, Kayden HJ, Hussain MM. Transport of vitamin E by differentiated caco2 cells. J Lipid Res. 2006 Jun;47(6):1261-73.

142. Sane AT, Sinnett D, Delvin E, Bendayan M, Marcil V, Menard D, Beaulieu JF, Levy E. Localization and role of NPC1L1 in cholesterol absorption in human intestine. $\mathrm{J}$ Lipid Res. 2006 Oct;47(10):2112-20. 
143. Murota K, Storch J. Uptake of micellar long-chain fatty acid and sn-2monoacylglycerol into human intestinal caco- 2 cells exhibits characteristics of proteinmediated transport. J Nutr. 2005 Jul;135(7):1626-30.

144. Lampen A, Meyer S, Arnhold T, Nau H. Metabolism of vitamin A and its active metabolite all-trans-retinoic acid in small intestinal enterocytes. J Pharmacol Exp Ther. 2000 Dec;295(3):979-85.

145. During A, Harrison EH. Intestinal absorption and metabolism of carotenoids: Insights from cell culture. Arch Biochem Biophys. 2004 Oct 1;430(1):77-88.

146. Yi W, Akoh CC, Fischer J, Krewer G. Absorption of anthocyanins from blueberry extracts by caco-2 human intestinal cell monolayers. J Agric Food Chem. 2006 Jul 26;54(15):5651-8.

147. Reboul E, Richelle M, Perrot E, Desmoulins-Malezet C, Pirisi V, Borel P. Bioaccessibility of carotenoids and vitamin $\mathrm{E}$ from their main dietary sources. J Agric Food Chem. 2006 Nov 15;54(23):8749-55.

148. Hix LM, Lockwood SF, Bertram JS. Bioactive carotenoids: Potent antioxidants and regulators of gene expression. Redox Rep. 2004;9(4):181-91.

149. Raju M, Lakshminarayana R, Krishnakantha TP, Baskaran V. Micellar oleic and eicosapentaenoic acid but not linoleic acid influences the beta-carotene uptake and its cleavage into retinol in rats. Mol Cell Biochem. 2006 Aug;288(1-2):7-15.

150. Shantha N, Decker EA, Henng B. Comparison of methylation methods for the quantification of conjugated linoleic acid isomers. J AOAC Int. 1993;76:644-9.

151. Folch J, Lees M, Sloane Stanley GH. A simple method for the isolation and purification of total lipides from animal tissues. J Biol Chem. 1957 May;226(1):497509.

152. Chitchumroonchokchai C, Bomser JA, Glamm JE, Failla ML. Xanthophylls and alpha-tocopherol decrease UVB-induced lipid peroxidation and stress signaling in human lens epithelial cells. J Nutr. 2004 Dec;134(12):3225-32.

153. Watanabe K., Ferrario M., Klein ML. Molecular dynamics study of a sodium octanoate micelle in aqueous solution. J Phys Chem. 1988;92:819-21.

154. Mu H, Hoy CE. The digestion of dietary triacylglycerols. Prog Lipid Res. 2004 Mar;43(2):105-33.

155. Borne J, Nylander T, Khan A. Vesicle formation and other structures in aqueous dispersions of monoolein and sodium oleate. J Colloid Interface Sci. 2003 Jan $15 ; 257(2): 310-20$. 
156. Constantinides PP, Steim JM. Physical properties of fatty acyl-CoA. critical micelle concentrations and micellar size and shape. J Biol Chem. 1985 Jun 25;260(12):7573-80.

157. Ferruzzi MG, Failla ML, Schwartz SJ. Assessment of degradation and intestinal cell uptake of carotenoids and chlorophyll derivatives from spinach puree using an in vitro digestion and caco-2 human cell model. J Agric Food Chem. 2001 Apr;49(4):20829.

158. Liu CS, Glahn RP, Liu RH. Assessment of carotenoid bioavailability of whole foods using a caco-2 cell culture model coupled with an in vitro digestion. J Agric Food Chem. 2004 Jun 30;52(13):4330-7.

159. Yonekura L, Tsuzuki W, Nagao A. Acyl moieties modulate the effects of phospholipids on beta-carotene uptake by caco-2 cells. Lipids. 2006 Jul;41(7):629-36.

160. Christensen JO, Schultz K, Mollgaard B, Kristensen HG, Mullertz A. Solubilisation of poorly water-soluble drugs during in vitro lipolysis of medium- and long-chain triacylglycerols. Eur J Pharm Sci. 2004 Nov;23(3):287-96.

161. Su LJ, Arab L. Salad and raw vegetable consumption and nutritional status in the adult US population: Results from the third national health and nutrition examination survey. J Am Diet Assoc. 2006 Sep;106(9):1394-404.

162. van Greevenbroek MM, Robertus-Teunissen MG, Erkelens DW, de Bruin TW. Lipoprotein secretion by intestinal caco-2 cells is affected differently by trans and cis unsaturated fatty acids: Effect of carbon chain length and position of the double bond. Am J Clin Nutr. 1998 Sep;68(3):561-7.

163. van Greevenbroek MM, van Meer G, Erkelens DW, de Bruin TW. Effects of saturated, mono-, and polyunsaturated fatty acids on the secretion of apo B containing lipoproteins by caco-2 cells. Atherosclerosis. 1996 Mar;121(1):139-50.

164. Stevenson SA, Blanchard GJ. Investigating internal structural differences between micelles and unilamellar vesicles of decanoic acid/sodium decanoate. J Phys Chem B Condens Matter Mater Surf Interfaces Biophys. 2006 Jul 6;110(26):13005-10.

165. Woodford FP. Enlargement of taurocholate micelles by added cholesterol and monoolein: Self-diffusion measurements. J Lipid Res. 1969 Sep;10(5):539-45.

166. Hayashi H, Fujimoto K, Cardelli JA, Nutting DF, Bergstedt S, Tso P. Fat feeding increases size, but not number, of chylomicrons produced by small intestine. Am J Physiol. 1990 Nov;259(5 Pt 1):G709-19.

167. Boulanger A, McLemore P, Copeland NG, Gilbert DJ, Jenkins NA, Yu SS, Gentleman S, Redmond TM. Identification of beta-carotene 15, 15'-monooxygenase as a 
peroxisome proliferator-activated receptor target gene. FASEB J. 2003 Jul;17(10):13046.

168. DellaPenna D, Pogson BJ. Vitamin synthesis in plants: Tocopherols and carotenoids. Annu Rev Plant Biol. 2006;57:711-38. 